\title{
CONTINUISTA O RUPTURISTA, RADICAL O SENCILLÍSIMA: LA REORGANIZACIÓN DE MINISTERIOS DE 1887 Y SU DISCUSIÓN POLÍTICO-ADMINISTRATIVA
}

Este trabajo estudia la discusión pública en torno a la reorganización ministerial llevada a cabo en Chile en 1887. A partir del debate sobre si el gobierno de Balmaceda tuvo orientaciones económicas distintas con respecto al resto de la elite, el artículo analiza cuáles eran las concepciones administrativas de los distintos actores políticos de la época y si concebían a la administración pública, sus funciones y funcionamiento de manera similar o no. Se concluye que la reforma ministerial impulsada por Balmaceda significa una continuidad de las funciones ministeriales y que las concepciones administrativas de la elite se sustentaban en dos ideas fuerza: la distinción política-administración y la búsqueda por contar con empleados públicos meritorios y estables en sus puestos.

Palabras clave: administración pública, ministerios, reformas administrativas, pensamiento administrativo en Chile.

This works studies the public debate about Chile's 1887 ministerial reorganization. It begins with the debate regarding how different Balmaceda's government economic orientation was from the elite's. The article analyzes the administrative notions prevalent among different political actors of the period paying attention to similarities and differences in the way they conceived the tasks and the functioning of public administration. The article argues that Balmaceda's ministerial reform sought continuity in ministerial functions and that administrative notions shared by the elites were based on two main ideas: the distinction between politics and administration and the search for stable and worthy public employees.

Key words: Public Administration, Ministries, Administrative Reforms, Chilean Administrative Thinking.

Fecha de recepción: mayo 2007

Fecha de aceptación: diciembre 2007

* Universidad de Chile. Correo electrónico: dbarria@uc.cl 


\section{INTRODUCCIÓN}

El desarrollo de la administración pública chilena durante el siglo XIX puede ser trazado en dos etapas. Una primera, ocurre tras la instalación de la Constitución de 1833 hasta el año 1854, en la que se conforman las instituciones en el ámbito central, principalmente los ministerios, y se desarrolla la red de figuras y relaciones mediante las cuales la autoridad del Presidente de la República se debía desconcentrar territorialmente. Esto último quedó establecido en la ley de régimen interior de 1844 y la de municipalidades, el año 1854. El aparato administrativo se mantiene en pie hasta la década de 1880 , fecha en que comienza una fase en la que la administración pública, en gran medida, es reorganizada. Piénsese, a modo de ejemplo, en la reforma de los servicios de Hacienda en 1883, de régimen interior de 1885 , de municipalidades, en 1887 y 1891 , o la de la Contaduría Mayor, en 1888.

A partir de la década de 1860 disminuyó la creación de servicios, siendo los ya existentes los que comienzan a ser reorganizados ${ }^{1}$. Ese afán reorganizador, se da en un contexto en que el Estado chileno, tras triunfar en la Guerra del Pacífico y obtener para sí la riqueza salitrera de los territorios quitados a Perú y Bolivia, contaba con una holgura fiscal. A ello se agrega el afán del gobierno de Balmaceda por ampliar la esfera de acción gubernamental ${ }^{2}$.

Entre estas reformas, se encuentra la reorganización ministerial del año 1887. Tras la creación del Ministerio de Relaciones Exteriores y Colonización se terminó de configurar la estructura ministerial que se mantendrá hasta 1887. Esta organización, que rigió desde 1837, reconocía la existencia de cinco departamentos ${ }^{3}$ : Interior, Relaciones Exteriores, Justicia, Hacienda y Guerra y Marina.

El ministro del Interior dirigía dos departamentos, uno para el Interior y otro para las Relaciones Exteriores y debía encargarse de asuntos económicos, de Obras

1 Sobre el desarrollo de servicios durante el siglo XIX, véase Enrique Fernández, Estado y Sociedad en Chile, 1891-1931, Santiago, LOM Ediciones, 2003, 91. Sin embargo, debe tenerse en consideración que la información entregada ahí omite las reorganizaciones de servicios durante el siglo XIX, principalmente las ocurridas desde 1880 .

2 Archivo Nacional Histórico (en adelante ANH), Archivo Santa María, 2 de febrero de 1887, pieza A 7505. En esa carta, Balmaceda le expresa a Santa María que con la reforma ministerial se ampliaría la esfera de acción estatal y planteaba su deseo por enviar unos diez proyectos de ley en junio de 1887.

Sobre las reformas durante el gobierno de Balmaceda véase Julio Bañados Espinosa, Balmaceda, su Gobierno y la Revolución de 1891. Tomo I, Santiago, Centro de Estudios Bicentenario (1894) 2005, 545-558.

Tanto en el decreto-ley de 1837, como en las leyes de 1853 y 1887, existe una distinción implícita entre ministerio y departamento. Cuando se hacía referencia a un departamento, se estaba hablando de una estructura administrativa con plantas de empleados propias. En tanto, cuando se hablaba de ministerio, a lo que se estaba haciendo alusión era a la existencia de un departamento que estaba a cargo de un ministro. Por ejemplo, desde 1837 existía un departamento de Relaciones Exteriores, separado del de Interior. Sin embargo, ambos estaban a cargo de un solo ministro. Así, en 1871, fecha en que se supone se creó el Ministerio de Relaciones Exteriores, no nació ninguna institución sino que solamente se nombró un ministro a cargo de ese departamento, de manera exclusiva.

En este trabajo se usará indistintamente el término ministerio y departamento, para hacer referencia a las estructuras administrativas y no a la existencia de un ministro a cargo. 
Públicas y de Correos. El Ministerio de Justicia debía preocuparse de la relación con la Justicia, la Iglesia Católica, de emitir el Boletín de Leyes y de la educación. Al Ministerio de Hacienda se le encomendaba el cuidado de materias relacionadas con la hacienda, contabilidad y deuda pública, la Oficina de Cuentas, los impuestos y el presupuesto de la nación. En tanto Guerra y Marina entre sus funciones encontraban la preocupación por las Fuerzas Armadas, los armamentos existentes y las academias militares ${ }^{4}$.

En 1853, la organización ministerial se hizo más compleja, al ver los departamentos la aparición de secciones. En Interior, se crearon tres, referidas a los negocios de Gobierno, policía interior y Correos; de negocios relativos al régimen municipal y, por último a negocios referidos a Obras Públicas, censos, estadísticas y Colonización. En el Departamento de Relaciones Exteriores se creó una sección. En el Departamento de Justicia se crean las de Justicia y Culto y la de Instrucción Pública. El de Hacienda se dividió en las secciones de recaudación, administración e inversión de las Rentas Públicas y la de Agricultura, Minería, industria y comercio. El Departamento de Guerra se dividió en las de Ejército y Guardia Cívica. En tanto, en el Departamento de Marina se creó una sola sección ${ }^{5}$.

Hacia 1887, se reorganiza el trabajo ministerial, aumentando el número de departamentos a siete (Interior, Relaciones Exteriores y Culto, Justicia e Instrucción Pública, Hacienda, Guerra, Marina y el de Industria y Obras Públicas). Principalmente, lo que hizo esta reforma fue traspasar las materias de industria y obras públicas a un nuevo departamento, y las de culto a Relaciones Exteriores ${ }^{6}$.

Junto a la redistribución del trabajo en cada ministerio, la ley cambia la figura del oficial mayor por la del subsecretario, funcionario a cargo de la dirección general de los trabajos de las secretarías, el estudio y preparación de los asuntos que debían ser resueltos por el ministro, además de preocuparse de la marcha del ministerio y de estar atento a las reformas que este pudiera necesitar. El subsecretario, en caso de ser elegido parlamentario, debía optar entre ese nuevo cargo o el que ocupaba.

La nueva ley aumenta y diversifica los tipos de empleos en los ministerios, junto con mejorar sus sueldos. El decreto-ley de 1837 reconoce a oficiales mayores, primeros, segundos, terceros y de partes y porteros. La ley de 1853 incorpora jefes de secciones y oficiales auxiliares. En 1887 se nombra, además, a archiveros, archiveros generales y sus ayudantes, oficiales supernumerarios, junto con distinguir entre porteros primeros y segundos y entre mensajeros a caballo y a pie.

4 Germán Urzúa Valenzuela, Evolución de la Administración Pública Chilena (1818-1868), Santiago, Editorial Jurídica de Chile, 1970, 60-64.

5 Boletín de Leyes i Decretos del Gobierno (en adelante BLDG), Libro XXI, N ${ }^{\circ} 7,1853,374$ 378.

6 Las atribuciones de cada Ministerio se encuentran en $B L D G$, Libro LVI, N ${ }^{\circ}$ 6, 1887, 709727. Un año después, mediante ley del 22 de noviembre de 1888, el ramo de Colonización, que en la ley de reorganización estaba a cargo del Ministerio de Industria y Obras Públicas, pasó a estar bajo dependencia del Ministerio de Relaciones Exteriores y Culto. ver BLDG, Libro LVII, N ${ }^{\circ} 11,1888$, 2078-2079. 
La ley de 1887 también estableció los requisitos de credenciales educacionales que se solicitarían a los empleados. El decreto del 15 de febrero de $1837^{7}$ explicitaba que para los ministerios se buscaban empleados con buenas costumbres y una "decente comportación”, además de una “...educacion literaria que los haga capaces de desempeñas las varias funciones y trabajos que les son ordinariamente encargados". En cambio, la ley de 1887, señalaba que para ser oficial de número se requería la tenencia del título de bachiller en humanidades y tener 18 años de edad. En tanto, para ser oficial de número de primera clase o jefe de sección se exigía, además de lo ya señalado, tener conocimientos de Derecho Público y Administrativo y haber aprobado otros cursos universitarios específicos para cada departamento.

Este trabajo estudia la discusión que se dio entre los actores políticos de la época y en los medios de prensa, con respecto a la reforma ministerial. En específico, intenta analizar si los distintos actores políticos concebían a la administración pública, sus funciones y funcionamiento de manera similar o no.

En la segunda sección se presentan las principales visiones que la historiografía entrega sobre la administración pública y las reformas que ella sufrió durante el gobierno de Balmaceda. En la tercera sección se muestra, a partir del análisis cuantitativo de algunos indicadores, cómo la administración pública sufrió un aumento de trabajo en las décadas anteriores a la reforma y cómo diversos actores políticos comenzaron a llamar a impulsar una reforma ministerial.

La cuarta sección muestra la discusión parlamentaria sobre el proyecto de ley presentado por el gobierno. Se intenta conocer los principales focos de discusión, haciendo especial énfasis en los puntos resistidos por los opositores a la reforma ministerial y las razones que esgrimían. En una quinta sección se muestra el balance que la opinión pública hace sobre la ley promulgada. Finalmente, se presentan algunas conclusiones.

\section{2. ¿QUÉ OBJETIVOS TENÍA LA REFORMA MINISTERIAL?}

Las reformas administrativas de la década de 1880 ocurren en un Chile decimonónico donde la actividad política estuvo dominada por un reducido grupo dirigente, compuesto por propietarios de tierra y comerciantes relacionados con la actividad minera quienes, desde el período de la independencia, habrían cooptado al Estado y aceptado ciertos cambios, sobre todo en el campo político -en el que abrazaron el ideario republicano-liberal-, para poder dirigirlos y mantener el "orden social"8.

7 Se solicitaba la certificación de ciertos cursos aprobados, dependiendo del departamento al cual se postulaba. Véase el decreto ley de Interior, del 15 de febrero de 1837. BLDG, Libro VII, N ${ }^{\circ} 3$, $1837,85-86$.

8 Ideas en este sentido se encuentran en Alfredo Jocelyn Holt, El peso de la noche. Nuestra frágil fortaleza histórica, Santiago, Planeta, 1999 y en Ana María Stuven, La seducción de un orden. Las elites y la construcción de Chile en las polémicas culturales y políticas del siglo XIX, Santiago, Ediciones Universidad Católica de Chile, 2000. 
DIEGO BARRÍA TRAVERSO / CONTINUISTA O RUPTURISTA, RADICAL O SENCILLÍSIMA 9

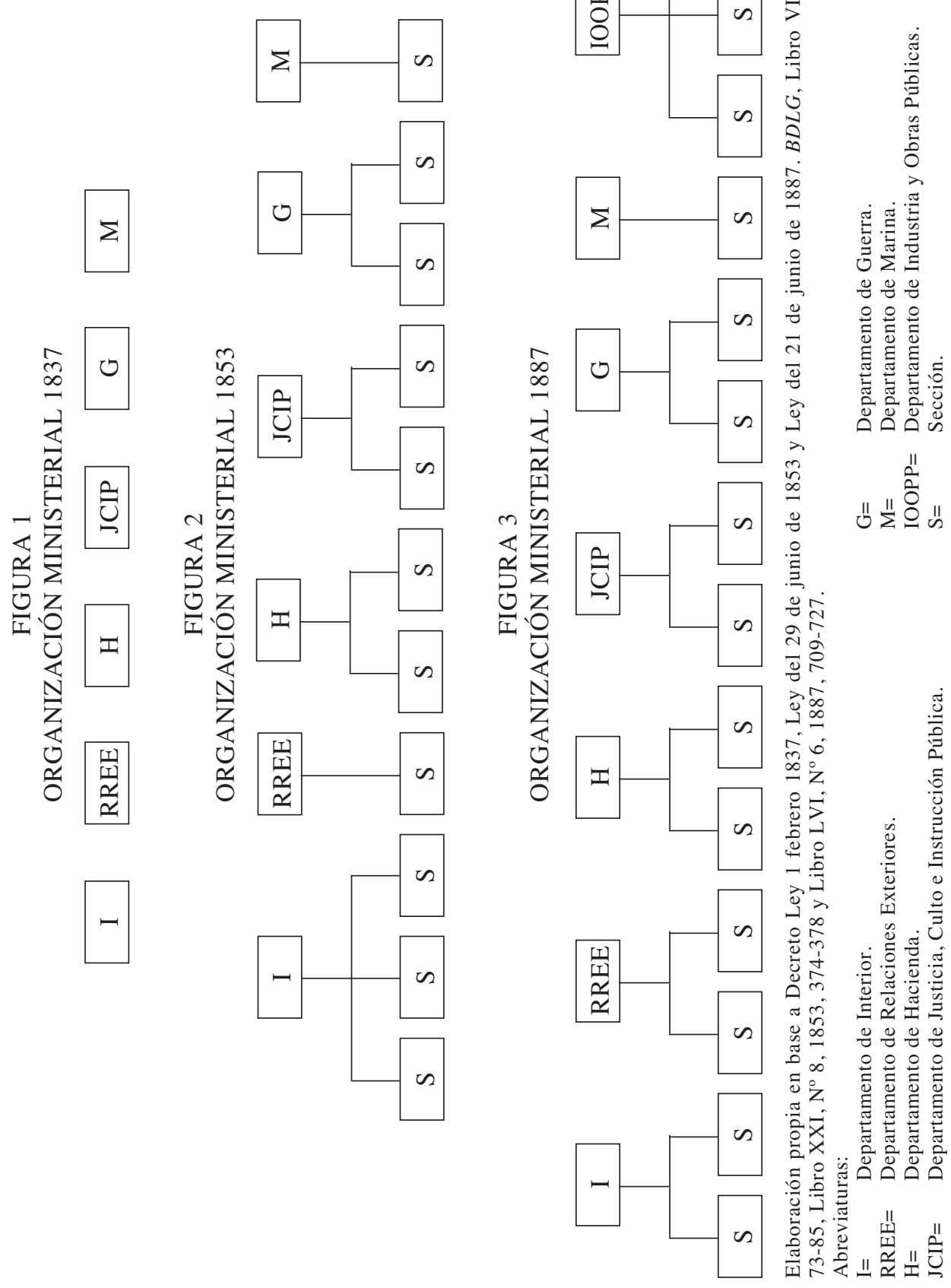


La elite, según Jocelyn-Holt, buscaba dominar al Estado para que este no se convirtiera en un actor autónomo, que pusiera en tela de juicio su poder político y social ${ }^{9}$. Para el autor, si bien con el desarrollo administrativo aparecieron funcionarios “...sumamente celosos de las prerrogativas de un Ejecutivo potencialmente omnímodo", por ejemplo Manuel Montt y Antonio Varas ${ }^{10}$, tras el equilibrio logrado entre las fuerzas políticas, desde 1860, la elite podía darse “...el lujo de considerar al aparato estatal administrativo como un elemento más del juego político, porque aún no aparecía una sociedad más plural y moderna"11. En este contexto, el mayor desarrollo administrativo que venía ocurriendo tras la Guerra del Pacífico, podría haber significado, para la elite, un potencial riesgo de una mayor autonomía estatal.

Aun cuando no existen estudios específicos sobre la administración pública durante el período, la historiografía ha aventurado tres visiones que permiten entender las reformas de la década de 1880. La primera, relaciona las reformas con un cambio de rumbo administrativo; la segunda destaca la estabilidad administrativa y la tercera afirma que, desde la segunda mitad del siglo XIX, comienza un proceso lento y de largo aliento que desemboca en la mayor intervención estatal durante el siglo XX.

La visión rutpurista se encuentra en autores como Hernán Ramírez Necochea. Para él, Balmaceda era un fervoroso partidario de la industrialización y la participación del Estado para activar la economía a través de obras públicas, la protección económica y el estimulo de la industria nacional. Bajo este programa, su gobierno habría tenido características revolucionarias.

Sin embargo, sostiene Ramírez Necochea, el Estado, a pesar de aumentar sus ingresos tras la Guerra del Pacífico, no contaba ni con una organización eficaz ni con instrumentos adecuados que le permitieran coadyuvar en la solución de los problemas nacionales, ni contribuir a aumentar el crecimiento económico ${ }^{12}$. Las reformas administrativas -entre varias que el autor nombra están la de ministerios, la Oficina de Estadística y el Tribunal de Cuentas-, venían a dar cuenta de los “...profundos reajustes en la maquinaria administrativa de la República, a fin de que ella sirviera de mejor forma a los imperativos del momento y a las intenciones que guiaban al Jefe de Estado"13.

Para Barros y Vergara, de modo contrario, el Estado desde 1830 hasta finales del siglo XIX realizó las mismas funciones, principalmente, cumplir la tarea de ser el guardián del orden público. Para los autores, los cambios ocurridos desde la segunda mitad del siglo XIX no vienen a alterar las funciones estatales sino que las

9 Alfredo Jocelyn-Holt, op. cit.

10 Alfredo Jocelyn-Holt, "Prácticas políticas: Chile, 1870-1886", en Estudios Públicos, N 69, verano 1998,443 .

11 Alfredo Jocelyn Holt, "La crisis de 1891: civilización moderna versus modernidad desenfrenada", en Luis Ortega (Ed.); La Guerra Civil de 1891. 100 años hoy, Santiago, Ediciones Universidad de Santiago, 1993, 30.

12 Hernán Ramírez Necochea, Balmaceda y la contrarrevolución de 1891, Santiago, Editorial Universitaria, 1969, 105-108.

13 Ibid., 155. 
formas en que se ejercía el poder. La obtención del salitre tampoco habría significado cambios en el funcionamiento, pero sí habría llevado a una lucha de la elite por controlar el Estado y distribuir, entre ella, los beneficios de los nuevos ingre$\operatorname{sos}^{14}$. En este contexto, podría pensarse que existía un consenso en lo administrativo, durante el siglo XIX. Barros y Vergara destacan que tras 1891 hasta 1914 las decisiones de la elite en materia económica son tomadas consensuadamente ${ }^{15}$.

Encina, por ejemplo, ha afirmado la tesis de la continuidad administrativa. Al respecto señala que

"Durante el período [de Balmaceda] no se reestructuró la administración, como erradamente ha solido decirse, sino que se desarrolló y adaptó a las nuevas exigencias del país el legado de Montt. Casi no hubo ramo que no recibiera ensanches y mejoras, que en algunos casos tomaron las proporciones de una verdadera reorganización"16.

Esa continuidad seguiría con posterioridad a 1891, pues si bien los ministros eran aves de paso, los subsecretarios y jefes de sección en las oficinas públicas, continuaron con la "correcta y expedita marcha que la administración traía desde los días de Portales, Rengifo y Tocornal"17.

Edwards Vives también adscribe a la idea de la continuidad de las oficinas públicas. En su visión, la "espléndida organización administrativa" dio muestras de solidez durante la Guerra del Pacífico, destacándose el legado de Portales ${ }^{18}$, que implicaba continuidad del orden legal y la existencia de una administración “...tradicionalista, ordenada y decorosa...". A pesar de ser inerte, para Edwards, la administración se encontraba bien organizada desde la instalación de la "República en forma", no obstante presentar, en los últimos años del período 1891-1924, ciertos rasgos de desquiciamiento debido a que, a pesar del envejecimiento de las leyes, no fue tocada, salvo en detalles ${ }^{19}$.

Bowman y Wallerstein han presentado evidencia respecto a la continuidad de las orientaciones económicas de los gobiernos que siguieron a la caída de Balmaceda. Los autores, a través de un análisis de las políticas públicas desde el gobierno de Balmaceda hasta 1924, no encuentran mayores cambios en cuanto a priorización de ámbitos de acción. Si bien el gobierno de Jorge Montt (1891-1896) redujo

14 Luis Barros y Ximena Vergara, "Los Grandes Rasgos de la Evolución del Estado en Chile", en Estudios Sociales, № 5, 1975, 148-149.

15 Luis Barros y Ximena Vergara, "La Guerra Civil del 91 y la instauración del parlamentarismo", en Revista Latinoamericana de Ciencias Sociales, N 3 Junio 1972, 86.

16 Francisco Encina, Historia de Chile, Tomo XIX, Santiago, Editorial Nascimento, 1951, 329-330.

17 Francisco Encina, op. cit. Tomo XX, 342-343. Julio Heise le asigna el mismo rol a estos funcionarios en la preservación de la continuidad administrativa, Historia de Chile. El Período Parlamentario, 1861-1925. Tomo I, Santiago, Editorial Andrés Bello, 1974, 303.

18 Para Encina, el legado moral de la obra de Portales se manifestaría en el ordenamiento de la administración y en la conformación de un cuerpo funcionario probo. Ello habría provocado una correcta marcha administrativa, gracias a que los funcionarios se esmeraban en ser honrados. Francisco Encina, Portales, Tomo I, Santiago, Editorial Nascimento, 1934, 311-312 y Tomo II, 343.

19 Alberto Edwards Vives, La fronda aristocrática en Chile, Santiago, Editorial Universitaria, 1928, 159, 198 y 209. 
los gastos durante los primeros 3 años, con posterioridad se mantuvo el nivel en diversos ámbitos, salvo educación. Además, los autores destacan que tras la caída de Balmaceda el Ministerio de Industria y Obras Públicas no fue eliminado ${ }^{20}$.

Existe una tercera visión, que plantea la existencia de un proceso de largo plazo, en el que la intervención estatal en la economía y en la sociedad van en aumento. Para Germán Urzúa Valenzuela, el gobierno de Balmaceda viene a terminar una primera etapa de la administración pública, caracterizada por un manejo de los asuntos vía decisiones gubernamentales en desmedro de la legislación. En esta primera etapa, la voluntad del Presidente de la República pesaba en los nombramientos de empleados y la administración se encaminaba a resguardar la libertad de los particulares. El período se habría caracterizado por una escasez del erario y los negocios que atender. La llegada de Balmaceda, significó, en su opinión, una ampliación de la esfera de intervención estatal, por ejemplo, en materia de salud la que se habría suspendido con la derrota de Balmaceda, no obstante acumular, silenciosamente, elementos que estallarían en $1920^{21}$.

Según Sagredo, los propósitos de Balmaceda eran hacer del Estado el principal instrumento de progreso del país, en los ámbitos moral, intelectual y material. Tendría el rol de ser “...la base del engrandecimiento de la República, el vehículo que conduciría a la nación a mejores y más elevados destinos...”. Ello a pesar de que, hacia 1882, Balmaceda creía que el Estado era “... un mal empresario y mal industrial y solo debe tomar por su cuenta aquellas obras de reconocida utilidad para el progreso de la nación, pero que como negocio no conviene a los particulares y por tanto las aceptan" 22 . El cambio de opinión se habría dado porque Balmaceda comenzó a creer que “...el tiempo de los privilegios sectoriales exclusivos se había acabado; las líneas de excepción, que era la forma en que el Estado tradicionalmente había intervenido en la vida nacional, ya no era algo tan factible ni útil"'23.

Balmaceda se inscribe en una etapa en que aparecen los orígenes del intervensionismo estatal. Sus ideas económicas, dice Sagredo, no constituyen ninguna novedad con respecto al pensamiento existente. En la época, según el autor, "El pragmatismo proteccionista es entonces el elemento que da continuidad a las políticas económicas existentes en el Chile republicano y, fruto de él, los cambios que en la concepción sobre el papel del Estado en la economía se han producido desde 1810 en adelante" 24 .

20 John Bowman y Michael Wallerstein, "La caída de Balmaceda y las finanzas públicas en Chile. Nuevos datos para un antiguo debate", en Revista de Ciencia Política Vol. V, No 1 1983, 127-129.

21 Germán Urzúa Valenzuela, op. cit., 33-35.

22 Rafael Sagredo, "Balmaceda y los orígenes del intervensionismo estatal" en Luis Ortega, op. cit., 40-41.

23 Rafael Sagredo, "Balmaceda, político liberal”, en Manuel Loyola y Sergio Grez (Comp.), Los proyectos Nacionales en el Pensamiento Político y Social Chileno del Siglo XIX, Ediciones Universidad Católica Cardenal Raúl Silva Henríquez, 2002, Santiago, 91.

24 Rafael Sagredo, Vapor al norte, tren al sur. El viaje presidencial como práctica política en Chile. Siglo XIX, Santiago, DIBAM-El Colegio de México, 2001, 198. 
Para Villalobos y Sagredo, el gobierno de Balmaceda representó una acción oficial más precisa y con medidas concretas. En esta línea se enmarca la creación del Ministerio de Industria y Obras Públicas, el que tenía a su cargo, más que planes acabados, la realización de ideas generales, utilizando los recursos disponibles. El nuevo departamento, en su visión, representaba

“...una especie de ministerio de economía, en el que se concentraban diversas funciones y reparticiones, hasta entonces dispersas y que ahora podían realizar sus trabajados de manera más coordinada, a la vez que el ministro del ramo podía imprimir alguna orientación global a la economía del país"25.

Eduardo Cavieres concuerda en ver una tendencia de largo plazo, nunca cuestionada en el Chile decimonónico, que hacía que se marchara hacia la conformación de una participación estatal a la sociedad más fuerte. Para el autor, ni para liberales ni conservadores, el apoyarse en el Estado era perder independencia, en la medida que se estuviera al frente de él ${ }^{26}$.

En este trabajo se plantea que la reforma ministerial de 1887 pareciera ser un intento por dar una mejor distribución del trabajo ministerial, junto con actualizar las plantas de empleados y los salarios de estos, estancados hace 34 años. De esta manera, la reforma no tendría un objetivo rupturista. Más bien, lo que se buscaba era ajustar las oficinas ministeriales a un nuevo contexto. Sin embargo, un análisis de todas las reformas del gobierno de Balmaceda parece sugerir que ellas mezclaron cambios en la administración y sus ámbitos de acción -como la política de salud $^{27}$-, junto con reacomodos de instituciones, que mantenían sus ámbitos de acción y funciones tradicionales.

\section{El AUMENTO DEL TRABAJO ADMINISTRATIVO. 1865-1891}

Cuando se habla del crecimiento estatal, principalmente tras la Guerra del Pacífico, generalmente se enfoca la cuestión desde la perspectiva fiscal. Si bien como indicador el gasto fiscal permite mostrar en qué áreas el Estado interviene y cuáles son sus prioridades presupuestarias (y políticas), tiene ciertas falencias a la hora de

25 Sergio Villalobos y Rafael Sagredo, El proteccionismo económico en Chile. Siglo XIX, Santiago, Instituto Profesional de Estudios Superiores Blas Cañas, 1987, 188.

26 Eduardo Cavieres, "Anverso y reverso del liberalismo en Chile, 1840-1930", en Historia Vol. $34,2001,42-43$ y $58-59$.

27 Illanes plantea que durante el siglo XIX temas como la salud habrían estado en manos de una institucionalidad privada, no ocupando un lugar preponderante en las preocupaciones del Estado, el que mostraba un "...rol meramente subsidiario en este sentido, descansando más bien en la Iglesia, la beneficencia privada y la educación universitaria, la responsabilidad directa en materia de salud de la población" (1993: 54). Sin embargo, a partir de la década de 1880, "El Estado policial, encargado solo del resguardo del orden público y social, al adquirir funciones de Estado-sanitario, cambiaba subrepticiamente y en la práctica histórica misma, de carácter, prefigurando el rol del Estado protectorlegislador social, propio del siglo XX”. María Angélica Illanes, “...En el nombre del pueblo, del Estado y la ciencia (...)”. Historia Social de la Salud Pública, Chile 1880-1973, Santiago, Colectivo de Atención Primaria, 1993, 54 y 65. 
hablar de cargas de trabajo administrativo, ya que no todo el trabajo estatal implica gastos imputables al presupuesto

Por ello, en esta sección se presenta otro indicador de actividad estatal: el número de decretos por año. La ventaja de este es que permite mostrar de mejor manera las variaciones del trabajo administrativo, ya que los actos de la administración se realizan a través de decretos.

\section{CUADRO 1}

DECRETOS POR RAMO, 1879-1892

\begin{tabular}{lcccccccc}
\hline Interior & $\begin{array}{c}\text { Relaciones } \\
\text { Exteriores }\end{array}$ & $\begin{array}{c}\text { Justicia, } \\
\text { Culto e } \\
\text { Instrucción }\end{array}$ & & Hacienda & Guerra & $\begin{array}{c}\text { Industria } \\
\text { y Obras } \\
\text { Públicas }\end{array}$ & $\begin{array}{c}\text { Títulos } \\
\text { todos los } \\
\text { ministerios }\end{array}$ & Total \\
\hline 1879 & 1.366 & 223 & 1.125 & 1.710 & 5.746 & & 3.033 & 13.203 \\
1880 & 1.180 & 149 & 3.660 & 1.999 & 6.108 & & 4.562 & 17.658 \\
1881 & 1.682 & 165 & 1.370 & 2.887 & 6.784 & & 7.234 & 20.122 \\
1882 & 1.743 & 205 & 1.445 & 2.647 & 7.036 & & 4.340 & 17.416 \\
1883 & 2.981 & 155 & 2.027 & 3.041 & 7.104 & & 5.954 & 21.262 \\
1884 & 2.606 & 256 & 3.284 & 2.658 & 6.765 & & 4.825 & 20.394 \\
1885 & 2.153 & 302 & 2.182 & 2.231 & 5.144 & & 4.218 & 16.230 \\
1886 & 2.068 & 442 & 1.800 & 3.520 & 4.036 & & 4.353 & 16.219 \\
1887 & 2.295 & 260 & 2.240 & 2.630 & 3.664 & 1.200 & 4.736 & 17.025 \\
1888 & 3.060 & 428 & 3.717 & 3.145 & 4.878 & 3.279 & & 18.507 \\
1889 & 4.673 & 1.467 & 5.962 & 3.925 & 3.591 & 3.285 & & 22.903 \\
1892 & 4.219 & 662 & 5.167 & 3.991 & 7.270 & 2.220 & & 23.529 \\
\hline
\end{tabular}

Fuente: Memoria presentada por el Ministro de Hacienda al Congreso Nacional, Santiago, Imprenta Nacional, 1880-1893, Anexo: Memorias de la Contaduría Mayor, 1880-1887 y Memoria del Presidente del Tribunal de Cuentas, 1888-1893.

Entre 1879 y 1892 , el número de decretos expedidos por la administración del Estado creció 1,78 veces. Si bien, después de la Guerra del Pacífico, el total de decretos anuales se redujo, en los años 1885 y 1886, hacia 1887 se volvió a experimentar un crecimiento, que en 1889 llegó a un 23,75\% con respecto al año anterior.

Los casos de los ministerios de Interior y Hacienda, durante el gobierno de Balmaceda muestran que el trabajo administrativo puede aumentar, a pesar de que el gasto fiscal disminuya. Probablemente, debido al traspaso de inversiones en obras públicas hacia el nuevo ministerio, Interior y Hacienda vieron una tasa de variación anual del gasto negativa, entre 1887 y 1891. Podría suponerse que el traspaso de los gastos pudo haber provocado, a su vez, un traspaso del trabajo asociado a las obras públicas, cuestión que habría generado una disminución del trabajo de estas carteras. Sin embargo, la tasa de variación anual de decretos en el período fue positiva, lo que hace suponer que, a pesar de librarse de las obras públicas, estos ministerios no se vieron más aliviados de trabajo. 


\section{CUADRO 2}

\section{TASA DE VARIACIÓN ANUAL DE DECRETOS Y GASTO POR RAMOS 1879-1891 \\ PROMEDIOS DE PORCENTAJES DE VARIACIÓN ANUAL}

\begin{tabular}{lccccc}
\hline & $\begin{array}{c}\text { Decretos } \\
1882-1886\end{array}$ & $\begin{array}{c}\text { Decretos } \\
1887-1892\end{array}$ & $\begin{array}{c}\text { Gasto fiscal } \\
1865-1881\end{array}$ & $\begin{array}{c}\text { Gasto fiscal } \\
1882-1886\end{array}$ & $\begin{array}{c}\text { Gasto fiscal } \\
1887-1891\end{array}$ \\
\hline Interior & 4,3 & 12,9 & 3,0 & 7,7 & $-5,6$ \\
Relaciones Exteriores & 21,1 & 20,5 & 1,1 & $-7,9$ & 2,6 \\
Justicia, Culto e Instrucción & 5,6 & 18,1 & 1,5 & 5,7 & 0,1 \\
Hacienda & 7,3 & 8,6 & 1,6 & 4,45 & $-1,1$ \\
Guerra y Marina & $-14,9$ & 14,6 & 9,4 & $-33,3$ & 53,1 \\
Industria y Obras Públicas & - & 13,0 & - & - & 0,73 \\
Total $^{28}$ & $-1,7$ & 6,6 & 4,9 & $-3,1$ & 7,29 \\
\hline
\end{tabular}

Fuente: Elaboración propia en base a Cuadro 1 y Markos Mamalakis, Historical statistics of Chile. Vol. 6 Government services and public sector and a theory of services, Westport, Grenwood Press, 1989, 225-226.

Las cifras agregadas muestran que durante el gobierno de Balmaceda, junto con el gasto, aumentó la carga de trabajo de la administración pública, revirtiéndose una tendencia, tras el fin inmediato de la Guerra del Pacífico a reducir la actuación estatal. De todas formas, a pesar de que durante el período de Santa María los decretos mostraron una tasa de variación anual negativa, la carga de trabajo de la administración hacia 1886 era mayor que en 1879, cuando comenzó el conflicto bélico. Esta cuestión fue percibida por el mundo de gobierno.

Durante 1886, comenzaron a aparecer opiniones dentro del gobierno con respecto a la necesidad de reformar la administración pública y, particularmente, los ministerios. Un ejemplo de esa preocupación son las Memorias presentadas por los ministros de Hacienda y Guerra y Marina durante ese año. El titular de Hacienda, Hermógenes Pérez de Arce, consideraba a la reforma de su cartera necesaria para poder complementar las anteriores reformas del ramo ${ }^{29}$.

28 Incluye ítem "Títulos de todos los Ministerios".

29 En 1875 se reorganizaron las oficinas de Hacienda. Mediante la ley del 22 de diciembre de ese año, se conformaron seis servicios, cada uno encargado de una tarea especializada: 1) Corte de Cuenta: Le correspondía examinar las cuentas de personas o instituciones que manejaran fondos públicos y realizar el juicio de Cuentas; 2) Dirección de Contabilidad General: Llevaba las cuentas generales de la Hacienda Pública, además de las cuentas relacionadas con las deudas internas y externas; 3) Dirección de Tesoros y Amonedación. Debía registrar los movimientos de dinero, comprar oro y plata para el proceso de amonedación y llevar registro de los contribuyentes e imprimir documentos para cobrar los impuestos; 4) Dirección de Impuestos y Crédito Público: Estaba encargada de emitir los bonos requeridos para los empréstitos internos y llevar la contabilidad de los billetes emitidos por los bancos; 5) Dirección de Aduanas: Su función era la de dar cuenta de los rendimientos de los aranceles. Debía emitir un informe de ello a la Dirección de Contabilidad; 6) Tesorerías Provinciales y Departamentales: Estaban encargadas de administrar los bienes del Estado y de recaudar rentas, impuestos y créditos fiscales en la jurisdicción de su competencia. 
En su visión, con la reorganización se podría responder con “....acierto i rapidez a los mui interesantes problemas que todos los dias exijen una solucion inmediata, en materias que, o bien afectan al desarrollo de la riqueza pública, a los intereses fiscales, o a mui graves intereses particulares". Para el ministro, el personal era deficiente para poder hacer frente a los estudios necesarios en diversas materias como "...contribuciones, contabilidad, deuda esterior e interior, negocacion de guano, papel moneda i papel bancario, impuesto de aduana i sus tarifas, sociedades anónimas i bancos de emision, matrículas de patentes i rol del impuesto agrícola, agrícultura, minería, etc.”.

El problema, para Pérez de Arce, tenía relación con la falta de reajustes de los sueldos, estancados desde 1853. Con bajas remuneraciones, decía, “... no se puede exijir mas trabajo que el de poner en limpio i copiar la correspondencia", ni se podían conseguir jefes de sección u oficiales para las secretarias. Esta cuestión generó preocupación por parte de los oficiales que se desempeñaban en la secretaría de Hacienda, quienes en 1884 recurrieron al ministro de la época para solicitarle que tomara medidas para mejorar sus remuneraciones (50 pesos mensuales), en circunstancias que otros empleos del ramo de Hacienda, “... por inferior que sea no se le ha señalado jamas una remuneración menor de sesenta (60) pesos mensuales..."30.

Junto a los bajos sueldos, Pérez de Arce daba cuenta del aumento de las funciones de Hacienda, lo que se graficaba en que el presupuesto de 1853 ascendía a $\$ 4.600 .000$, mientras que el de 1886 alcanzaba $\$ 36.000 .000$. Para el ministro, de no realizarse una reorganización de la planta de empleados, se correría el riesgo

“...de que la jestion administrativa de los mas graves intereses del pais vayan gradualmente descompaginándose, bajo la influencia de los gastados resortes que creó la lei del año 53, i cuya subsistencia, por algunos años mas, marcaría indudablemente una sensible decadencia en nuestra colosa actividad administrativa, acreditada con tan honrosas tradiciones" 31 .

El ministro de Guerra, Carlos Antúnez, al entregar la Memoria de su cartera para igual período, comparte con Pérez de Arce la necesidad de reformar el trabajo en las oficinas ministeriales. Acusaba la falta de personas necesarias para desempeñar el trabajo al que se tenía que responder. De igual manera, argumentaba que la necesidad de la reforma se relacionaba con los cambios ocurridos en el país desde que se dictó la ley de 1853. Decía el ministro:

Con posterioridad, en 1883, se dicta la ley orgánica de la Dirección de Tesoro y la Dirección de Contabilidad, debiendo la última comprobar y verificar los actos de los administradores de fondos que causaran ingresos o egresos al erario. Un año después se dicta una ley referente a la formación del Presupuesto y las cuentas de inversión. Germán Urzúa Valenzuela, op. cit., 95-102.

30 AMH, Archivo Ministerio de Hacienda (en adelante AMH), Volumen 1477 "Solicitudes empleados 1884 ", s/f.

31 Memoria presentada por el Ministro de Hacienda al Congreso Nacional en 1886, Santiago, Imprenta Nacional, 1886, CXI-CXIII. 


\begin{abstract}
"Reconozco el celo i laboriosidad con que, en jeneral, se han desempeñado los empleados que han estado bajo mi inmediata dependencia; pero reconozco tambien que ha llegado el momento de dar nueva forma, mas en armonía con las necesidades actuales de la Administracion, a un sistema que cuenta a la fecha treinta i cuatro años de existencia i que fue ideado para una época en que los negocios administrativos abarcaban una esfera de accion mucho mas limitada.

Hoy, tal como están organizadas las cosas, los Ministros de Estado carecen aun del tiempo material para consagrarse al estudio de los negocios de alguna trascendenia, absorvidos como se hallan por los detalles nimios del despacho diario i por las tenciones que imponen los deberes parlamentarios. Necesitan, pues, de ausiliares que los desempeñen en esta parte de su labor, ayudados por un cuerpo de empleados reducido pero idóneo, que, encontrando alicientes para consagrarse por entero a la carrera administrativa, tomen esta como una situacion estable i no de mero tránsito para dejarla en primera oportunidad" 32 .
\end{abstract}

La necesidad de reformar el servicio ministerial fue una preocupación que también apareció en la prensa. En octubre de 1886, solo dos semanas después que asumiera el Presidente Balmaceda ${ }^{33}$, diversos medios llamaron al gobierno a llevar adelante la reforma.

El Mercurio inició la discusión, planteando que desde hace seis o siete años se encontraba pendiente una discusión en torno a una reorganización de los ministerios, “...bajo una forma enteramente diversa y sin duda mejor que la que hoy dia tienen". Uno de los principales problemas identificados por el medio era el que “...cada oficina de ministerio está compuesta de un número exajerado de empleados y al trabajo que en ellas se hace no corresponde de ninguna manera a tan crecido personal". Junto a ello, acusaba una demora en el despacho de los negocios ministeriales, lo que obligaba a los propios interesados a ser agentes para activar resoluciones. Llamaba la atención también sobre las quejas existentes por la demora con que se contestaban las consultas planteadas por los servicios públicos a los ministerios.

El medio proponía que el subsecretario tuviera un mayor número de funciones que cumplir y que el ministro solo estuviese involucrado en las resoluciones, además de que fuese el subsecretario, y no el ministro, el que contestara interpelaciones relativas a asuntos administrativos. Finalizaba, solicitándole al gobierno que

32 Memoria presentada por el Ministro de Guerra al Congreso Nacional en 1886, Santiago, Imprenta Nacional, 1886, XXXVI-XXXVII.

33 En todo caso, no fue el único debate sobre reformas que apareció. Cada medio intentó incorporar los temas que más le preocupaban en lo que pareciera haber sido una etapa en la que se estaba construyendo la agenda del nuevo gobierno. Los medios conservadores intentaron colocar rápidamente el problema municipal en la discusión pública. Desde el 7 de septiembre de 1886, El Independiente comienza a publicar artículos referentes al tema. El 23 de septiembre, el gobiernista Los Debates informaba sobre la posición del Cabildo de Santiago en favor de la reforma y las actividades que realizaban para conseguirla. La Libertad Electoral también colocó el tema en su edición del 22 octubre 1886, junto a otras reformas por las que abogaba, por ejemplo, en el ámbito judicial. A diferencia de la reforma de ministerios, los medios no lograron colocar el tema municipal en la agenda del gobierno, cosa que si pudieron hacer los parlamentarios hacia junio de 1887. 
sacase del estante en que se encontraba el proyecto antiguo, al que se hizo alusión anteriormente, y que lo enviase al parlamento ${ }^{34}$.

En el debate aparecieron otros diagnósticos, menos radicales, sobre cómo mejorar el servicio. Los Debates consideraba que la organización del trabajo ministerial no era excesivamente mala, por lo que no se debían buscar reformas radicales, sino tomar una organización muy semejante a la existente hacia ese momento. No veía para qué "...se emprenderia el trabajo de reorganizar cuando en realidad talvez no se llegaria a otro resultado que al dar nombres nuevos a cosas mui conocidas". Reconocía que los asuntos administrativos sufrían retrasos molestos y perjudiciales, pero señalaba que “... este defecto puede corregirse fácilmente i con solo introducir en los hábitos rutinarios de nuestras oficinas públicas algunas innovaciones que no son mui sustanciales".

Una primera medida era reducir el papeleo en las oficinas públicas, legado de la administración colonial ${ }^{35}$. Otra propuesta era aliviar a los ministros de la obligación de suscribir las transcripciones de los decretos supremos. Se preguntaba el medio:

“¿Qué necesidad hai de que sean los mismos ministros los que tengan que dictar la mayor parte de las providencias de trámite que son de las que se llaman de cajón, i los que deban suscribir las transcripciones de los decretos? Por lo común, la operación de poner la forma al pie de esos documentos impone a los ministros un trabajo material de una, dos i más horas diarias. Entre tanto, seguramente bastaría que los oficiales mayores suscribiesen las transcripciones, como quiera que la transcripción de un decreto es simplemente la certificación de que la copia está conforme con la original”.

Junto a ello, planteaba que podían tomarse algunas medidas tendientes a mejorar el trabajo de los empleados de las oficinas. Al respecto, señalaba que

"seria indispensable para estimular el celo de los empleados de los ministerios, para tenerlos siempre de competencia probada i para poder exijirles una mayor gama de labor seria la de aumentar sus sueldos que son absolutamente deficientes. Con decir que ellos son ahora los mismos que eran hace treinta o más años i que la planta de empleados tampoco se ha modificado en ese largo transcurso de tiempo, ya se comprenderán que no pueden ser equitativos los sueldos que se están pagando"36.

34 "Los Ministerios", El Mercurio, 2 de octubre de 1886.

35 El artículo contaba cómo se realizaba el proceso de pago de saldos de los estafetas hasta 1883. Se iniciaba con el informe que enviaba el estafeta al director general de Correos, el que era devuelto por este con la información del saldo a pagar. El estafeta hacía llegar la información al gobernador. Este enviaba al intendente, el que hacía lo propio con el ministro de Interior. El ministro remitía el informe al director general de Correos, quien debía verificar el saldo e informarle al ministro la suma correcta. Una vez que recibía esa información, el ministro la devolvía al intendente y este al gobernador, el que, a su vez, enviaba la orden de pago al tesorero fiscal, quien, finalmente, pagaba al estafeta. El artículo destacaba que este procedimiento fue simplificado por el entonces ministro Balmaceda. Los Debates, 5 de octubre de 1886.

36 Ibidem. 
Estas medidas, con las cuales se ganaría en expedición, no requerían, según el medio, una ley de reorganización ministerial, sino tan solo un decreto supremo por parte del gobierno.

La Época concordaba con que la mejora del servicio podía hacerse a través de decretos supremos. Proponía que los ministros solicitaran a los oficiales mayores un doble informe, donde se detallara la situación de los procedimientos de los ministerios hasta ese día y se propusieran mejoras para corregir "...todo lo que redunde en gasto de papel i de tiempo". Además, destacaba la utilidad de crear incentivos para los empleados públicos, entre ellos, mejorar los sueldos “...dentro de los estrechos límites que aconseja el plan de economías del erario nacional", colocar en los ministerios a jóvenes con buenos antecedentes del colegio e inteligentes, dando así “...garantías de ser empleados útiles i laboriosos...”, además de estimular el ascenso por antigüedad y, excepcionalmente, por cualidades y merecimientos ${ }^{37}$.

En tanto, El Independiente planteaba que para que existiera regularidad en los servicios, la fijación de un número de horas de trabajo, y de inicio de estos, era primordial. Además, se mostraba favorable a que las plantas de empleados fueran escogidas en base a criterios no políticos. Señalaba que "Con el nombre de moralidad entendemos que la justicia presida a todos los actos, especialmente al nombramiento i ascensos de empleados" 38 . Además, creía que debían aumentarse los sueldos, reducirse el número de empleados e incrementarse el trabajo de los que quedaran "...en cuanto sea justo i en cuanto cada puesto llegue a serlo realmente de valor i responsabilidad”. De esta manera, los ministerios estarían “...infinitamente mejor servidos de lo que lo están ahora" 39 .

La discusión en los medios de prensa fue recogida por el gobierno, que finalmente se decidió a presentar un proyecto de ley. El Mercurio se felicitó por el eco de su artículo del 2 de octubre, destacando que de la discusión en la prensa “...sacamos como resultado el hecho de la casi completa conformidad en que nos encontramos sobre la defectuosa situacion en que funcionan las oficinas del servicio ministerial". Planteaba que la solución de la situación ministerial no pasaba por suprimir algunos empleados y aumentar sueldos, sino que era "... menester proceder a una completa reorganizacion de este servicio y para ello elaborar un bien meditado proyecto de las atribuciones y trabajos que deben corresponder a cada empleado". Las propuestas eran: 1) Establecer horas de trabajo; 2) Evitar que entrara gente que hiciese renta o buscase ayuda para estudios universitarios o a otras labores; 3) Establecer una escala de ascensos, para que se pudiese hacer carrera como estimulo para mejorar desempeño. 4) Establecer un "sistema de certámenes" para obtener mejores empleados con "...mayor competencia y preparación" 40 .

\footnotetext{
37 "Innovaciones en el servicio de Ministerios", Los Debates, 6 de octubre de 1886.

38 "El Servicio de los Ministerios I", El Independiente, 7 de octubre de 1886.

39 "El Servicio de los Ministerios II", El Independiente, 8 de octubre de 1886

40 "Será un hecho", El Mercurio, 12 de octubre de 1886.
} 
Una vez que el proyecto de gobierno ya era un hecho, Los Debates abandonó su propuesta de mejoras "sencillísimas" vía decreto, entrando a analizar el problema de la carga de trabajo de cada ministerio. Al respecto, llamaba la atención sobre la cantidad de materias abarcadas por Interior, lo que hacía “...imposible que pueda ser convenientemente atendido por un solo ministro".

El periódico gobiernista volvía a sus propuestas del día 5 de octubre, que entregaban al subsecretario la tarea de reemplazar al ministro en el trabajo anterior a un decreto y en dar explicaciones al Congreso sobre asuntos administrativos. Las ventajas de estas medidas habrían estado dadas por la continuidad de servicio. Se “...ganaria en claridad porque, en todo caso, i cualesquiera que fuesen las modificaciones que sufrieran los gabinetes por causas políticas, los subsecretarios de estado permanecerian para hacerla marchar conservándole su necesaria unidad" 41 .

El Presidente Balmaceda ingresó al Senado el proyecto de reorganización, el que se discutió entre diciembre de 1886 y enero de 1887. En el mensaje que acompañó al proyecto de ley, Balmaceda daba a conocer sus apreciaciones con respecto al estado de las carteras de Estado. Estas tomaban en cuenta gran parte de los problemas apreciados en la prensa y por los ministros Pérez de Arce y Antúnez.

El diagnóstico de Balmaceda consideraba que se había creado una recarga de trabajo de los ministerios debido al “...desarrollo de las obras publicas i las necesidades progresivas de la industria..." ${ }^{42}$, lo que generaba problemas de método y severidad a la hora de invertir caudales públicos. Además, identificaba falta de preparación técnica en la ejecución de las obras públicas por parte de los diversos ministerios.

El Presidente creía que, para invertir los recursos públicos con “....acierto i economía”, debía crearse un ministerio de obras públicas, el que debería atender, además, la industria y la agricultura, “...los ramos fundamentales de la producción nacional...”. El Estado, debía, a través de este organismo, concurrir “...eficazmente a robustecer el progreso i las fuentes capitales de la producción jeneral..."43.

De esta forma, el proyecto creaba un nuevo departamento, de Fomento y Obras Públicas, el que se haría cargo de las obras públicas, el desarrollo de la industria y la colonización. En tanto, el manejo del Culto pasaba desde Justicia hacia Relaciones Exteriores. El mensaje presentaba las bondades que la reorganización de los ramos traería a cada uno de los ministerios. Interior se vería descargado de las obras públicas, lo que le imponía, hasta ese momento, “...tareas importantes i poco compatibles con las atenciones que requiere la dirección política de la República". Sobre el de Relaciones Exteriores señalaba que “...se desprenderá del ramo de Colonización i se hará cargo del ramo de Culto, que indudablemente está más en

41 Los Debates, 23 de octubre de 1886.

42 Boletín de Sesiones del Senado (en adelante BSS), Sesión $5^{\text {a }}$ Extraordinaria, 3 de diciembre de 1886,72 .

43 Ibidem. 
armonía con las relaciones estranjeras”. Mientras tanto, Justicia quedaría más descargado para “...consagrarse a la vasta labor de reforma i mejoramiento que la experiencia aconseja que nuestra cultura reclama en estos dos interesantes ramos del servicio nacional”. Por último, Hacienda y Guerra y Marina, “...se encontrarán desprendidos de trabajos que se encargarían al Ministerio de Obras Públicas, con evidente conveniencia para el funcionamiento regular i propio de dichos Ministerios" 44 .

Otra cuestión que importó al Presidente fue darle estabilidad a los primeros funcionarios de los ministerios, creándose la figura del subsecretario, además de mejorar las rentas que recibirían los empleados a cargo de los departamentos. Al respecto, señalaba que estas medidas eran “...garantía necesaria para dar estímulo a las aptitudes reconocidas i a la honorabilidad probada" 45 .

La discusión en la prensa se reaviva al conocerse el proyecto del gobierno. El Ferrocarril abogó porque se mantuviera el número de departamentos existentes hasta ese momento “...operando simplemente una division mas sistemada y lógica de las atribuciones de los departamentos del Interior y Relaciones Esteriores". Por ello, estos ministerios debían ser uno, pues, de esta manera, no se aumentaba "inútilmente" su número y se podría atender de mejor manera los resultados del servicio público, sin repercutir en el gasto. En su visión, los problemas de organización se debían a una defectuosa clasificación de atribuciones y no a la falta de personal.

Además, consideraba que el Ministerio de Fomento debía dividirse en secciones a cargo de personas idóneas. Llamaba la atención sobre la diferencia entre los intereses políticos y materiales. Para los primeros, se exigía “....ante todo versacion en las ciencias políticas y administrativas...", mientras que para los segundos, era necesario "...una competencia hasta cierto punto profesional en todo lo que se relaciona con las obras públicas en sus mas variadas manifestaciones". Para el medio, al darle un carácter no político al ministerio nuevo, "Habria unidad de pensamiento y de accion y una administracion mas arreglada, espedita y económica". Además, con una reforma de esta naturaleza, donde existiría un ministerio alejado de las cuestiones políticas, era más fácil llegar a un acuerdo en el legislativo. Ello, si se consideraba que "Su necesidad y las ventajas de su realización cuenta con el asentimiento jeneral ${ }^{46}$.

La Libertad Electoral concordaba en torno a la necesidad de que existiera un servicio encargado del fomento y las obras públicas. Sin embargo, cuestionaba el rango ministerial de la nueva oficina. El medio se preguntaba si no se podría cambiar el nuevo ministerio por dos direcciones generales, una de Fomento y otra de Obras Públicas, a cargo de empleados no políticos. O bien, si se aceptaba el nuevo ministerio, “... ¿no podria el resto de la tarea ser convenientemente distribuida entre cuatro, sin aumentar así el número de los cinco ministerios actuales,

44 Ibidem.

45 Ibidem.

46 El Ferrocarril, 2 de diciembre de 1886. Ideas similares fueron planteadas por el mismo medio en la edición del 22 de octubre del mismo año. 
que no parecen poco atendido el modesto lugar que Chile ocupa en la asamblea de las naciones?" 47.

El Independiente cierra la discusión, reiterando sus propuestas en torno a que los ministros no debían ocuparse de asuntos administrativos y que el personal no debía nombrarse por razones políticas. Volvía a la idea de que se debía contar con mejores sueldos que atrajeran mejores empleados. El punto central del artículo era establecer una distinción entre política y administración. Ello implicaba que

"El buen servicio de los Ministerio i la moralidad administrativa exijen de consuno (sic) que en los nombramientos se observen estas sencillas i elementales nociones de justicia. Si para nombrar a una persona como sub-secretario de Estado, eomo (sic) oficial mayor, o como jefe de seccion de un Ministerio, por ejemplo, se toma en consideración, mas que su competencia, honorabilidad i otros antecedentes de esta naturaleza, la mayor o menor constancia con que ha sido palaciego de Gobierno, es inútil que se aumenten los sueldos porque a esto no corresponderá un mejoramiento de empleados.

Es necesario, pues, que en la práctica, de hecho, se separe la política de la administración, para que así, libre esta de bajezas y pequeñeces, produzca los beneficios que debe producir" 48 .

Esta declaración se relacionaba con la acusación de otros medios, como La Libertad Electoral, que planteaban que el personal de la administración se elegía a través del nepotismo, de la exigencia de los amigos, los deudos y de los partidos, lo que atentaba, en su opinión, contra la regularidad administrativa, la que no se lograría “...si el personal que está encargado de ella no da garantías de competencia, de contraccion i de moralidad" 49 .

En tanto, El Mercurio veía en los exámenes para dotar los empleos la forma en que “...se desterrará de las salas de gobierno la plaga funesta de los empeños y las influencias políticas”, agregando que así “... alejariamos uno de los peligros mas probables del gobierno personal" 50 .

En la discusión de prensa hubo consenso en que se debía mejorar el trabajo de las oficinas ministeriales. No obstante, los grados de reforma, radical o "sencillísima" - y la forma (ley o decreto), no fueron materia de acuerdo. Tanto la prensa, como los personeros de gobierno compartían el análisis de que el trabajo en las oficinas ministeriales era deficiente. Para el gobierno, la recarga de trabajo, debido al paso del tiempo, era la principal causa. Resume la idea, el argumento planteado por Carlos Antúnez, ministro del Interior, para quien

47 El artículo llamaba la atención sobre “...la falta de precision científica con que el proyecto está redactado...". Señala que se usaban términos impropios, no ajustados al tecnicismo legal, además de criticar que se detallaba minuciosamente, haciendo poco claro el sentido de la ley. Criticaba, también la redundancia de palabras y de disposiciones de otras leyes, quitándole la concisión que debía tener el proyecto. Solo así se entendía, para este medio, el hecho que se le daba rango de autoridad a los ministros cuando solo eran secretarios que no tenían capacidades de dar órdenes por sí solos. "Secretarías de Estado", La Libertad Electoral, 8 de diciembre de 1886.

48 "Política i Administración", El Independiente, 19 de diciembre de 1886

49 La Libertad Electoral, 2 de octubre de 1886.

50 "Importante Decreto", El Mercurio, 29 de octubre de 1886. 
“... el desarrollo violento, puede decirse, que en los últimos años ha adquirido el servicio administrativo i las exigencias que han nacido a consecuencia de ese mismo desarrollo; se debe tambien a ... ciertos vicios i malos hábitos que han venido perpetuándose entre nosotros, como es la tarea parlamentaria, llevada ya al exceso, i la necesidad que esta tarea impone a los Ministros de desviar en parte su atención de los negocios que tienen a su cargo; se debe, por último, a la mala organización que hasta ahora han tenido los Ministros respecto a la distribución de los trabajos, i aun en el detalle mismo de las distintas oficinas que de ellos dependen" ${ }^{51}$.

La idea de que se debía contar con empleados públicos que fuesen competentes para el trabajo ministerial fue unánime. Muestra de ello son las varias medidas propuestas por distintos periódicos, tendientes a contratar personas idóneas e, incluso, establecer certámenes donde se seleccionaran empleados, de manera competitiva, de acuerdo a sus méritos. Ello, en el caso de los medios de oposición, llevó a atacar el ingreso de empleados por razones políticas y acusar un exceso de personal, cuestión no compartida por los ministros.

La difusión de la idea de que ingresaran a la administración empleados por sus antecedentes meritorios no era solo una bandera de lucha de la oposición contra un gobierno que contrataba personas por favores políticos, sino que formaba parte de la agenda del propio gobierno. Por ejemplo, el 26 de octubre de 1886, al mismo tiempo en que la prensa se discutía la posibilidad de que ingresaran personas por mérito a la administración, el gobierno,

"Considerando que es conveniente para el mejor servicio público que los nombramientos de empleados recaigan en personas que reunan los títulos de competencia i honorabilidad necesarios para desempeñar el puesto que se trata de proveer..."

dictaba un decreto donde se establecía un examen previo para el ingreso a las oficinas de Hacienda como la Contaduría Mayor, la Dirección del Tesoro y la Dirección de Contabilidad, puesto que sería la “...manera más práctica de apreciar la competencia de los aspirantes a ciertos puestos..." 52 .

\section{LA DISCUSIÓN EN EL PARLAMENTO}

En ambas Cámaras, el debate se produjo, principalmente, entre el ministro Antúnez y los parlamentarios del Partido Conservador ${ }^{53}$. De la activa participación de los conservadores en la discusión, el ministro del Interior señaló en la Cámara Baja que

51 BSS, Sesión $10^{\text {a }}$ Extraordinaria, 17 de diciembre de $1886,138$.

52 BLDG, Libro LV, $\mathrm{N}^{\circ} 10,1886,1081$.

53 En otras discusiones parlamentarias, como la del proyecto que creó el Tribunal de Cuentas, se repitió el hecho de que quienes hacieron uso de la palabra fueron el ministro del ramo al cual los proyectos trataban y los parlamentarios que se oponían al mismo, en su mayoría conservadores. Surge la interrogante si esto era una situación coyuntural o si, por el contrario, respondía a una práctica política asentada en la cual los parlamentarios de gobierno se limitaban a entregar sus votos. 
"Me parece lógico que los señores conservadores encuentren malo el servicio público. De aquí es que los veamos hoy como siempre, traer a la Cámara cargos mas o menos infundados, tanto contra la administración en jeneral como contra los hombres que la componen" 54 .

El proyecto fue resistido, principalmente, por los parlamentarios conservadores y algunos liberales sueltos, en lo relativo al aumento del número de ministerios, además de mostrar un resquemor hacia el posible aumento de facultades del Presidente de la República.

\title{
4.1 El tamaño del Estado y la evolución administrativa
}

Para un grupo de parlamentarios, el aumento de los ministerios resultaba innecesario, pues consideraban que el problema del funcionamiento administrativo estaba en la intervención política y no en razones propias de la administración. Se planteaba, además, que se rompería una tradición de "sobriedad fiscal". En esa línea, el diputado Blanco Viel, destacaban la sencillez de la administración pública como una cualidad de un sistema democrático ${ }^{55}$.

Los parlamentarios opositores al proyecto discutían el diagnóstico del gobierno respecto al aumento del trabajo administrativo. El diputado Barriga señalaba que "El incremento de la actividad nacional, por grande que el amor propio se lo imajine, no ha llegado a un estremo tal que justifique la imposición de nuevas cargas al Erario público". Para él, la deficiencia del trabajo no venía de la falta de empleados sino de la "notoria incompetencia i vicios" de la organización y régimen interno. Criticaba que todos los empleados fueran nombrados por el Presidente de la República. Esta situación venía a hacer incapaz de funcionar al "mecanismo administrativo", que

\begin{abstract}
"se funda en un sistema de responsabilidades sucesivas que a modo de ruedas dentadas van engranando las unas en las otras i transmitiéndose el impulso que reciben del motor o ajente principal. Si el engranaje no es perfecto, si alguna de las ruedas no funciona, si el más pequeño resorte no obedece, cualquiera de estas circunstancias bastaría para entorpecer o paralizar el movimiento de la maquina toda... Como ya he tenido el honor de manifestarlo, el vicio radical de nuestra administración no consiste en la falta de empleados, pues los hai suficientes, sino en la incompetencia que distingue a la mayor parte i en la inmoralidad que resulta de la intervención política"56.
\end{abstract}

La experiencia internacional también era usada por los opositores al aumento de ministerios como prueba de la inconveniencia de la medida. Carlos Walker Martínez planteaba que Argentina tenía 5 ministerios, Estados Unidos 6, Austria 7

54 Boletín de Sesiones de la Cámara de Diputados (en adelante BSCD), Sesión 6a Ordinaria, 16 de junio de 1887,95 .

55 Ibid., Sesión 83a Extraordinaria, 7 de mayo de 1887, 1201.

56 Ibid., Sesión 6a Ordinaria, 16 de junio de 1887, 91-92. 
“...siendo que Austria tiene más de 40 millones de habitantes, Estados Unidos 28 millones, etc. Vamos a colocarnos en la situación de las Islas de Sándwich en donde hai cuatro Ministros y solo 70 mil habitantes" ${ }^{27}$. El senador Altamirano también rechazaba crear ministerios en la medida que aumentara el trabajo. Planteaba que si el reino inglés siguiera esa idea, contaría con 70 u 80 ministerios en lugar de los 8 o 10 que tenía ${ }^{58}$.

Para el senador Melchor Concha y Toro, en lugar de crearse un sexto ministerio, se debía reorganizar el trabajo de los ya existentes. Para él, Chile era un país pequeño, que no podía pretender aumentar el número de ministerios a medida que desarrollaba su población y riquezas, “... porque esto seria apartarnos por completo de la senda que ha distinguido a la administración publica chilena, la modestia de su representación i la parsimonia de sus gastos". Esa misma idea era compartida por otros parlamentarios, como Eulogio Altamirano ${ }^{59}$. Ambos destacaban que aumentar el personal era crear más problemas para la administración.

Para el Senador conservador, José Clemente Fabres, no era necesario aumentar el número de ministerios, pues "un hombre solo puede bastar para dos, tres o cuatro ramos, si tiene ausiliares competentes... No considero necesario, pues, un nuevo Ministerio, sino que se dé a los Ministros ausiliares industriales a quienes consultar"60. Mostrando las bondades de su propuesta, señalaba que un ministro podría informarse en horas sobre temas que le llevarían meses de estudio por su cuenta.

Debido a que gran parte de la crítica hacía alusión a los gastos que un nuevo ministerio traería, el ministro Antúnez intentó defender el proyecto, reafirmando la existencia de "... necesidades reales i positivas que se hacen sentir" ${ }^{1}$, que justificaban los cambios impulsados por el gobierno, los que, de modo contrario a lo que se decía, traerían economías fiscales. Para él, los trabajos realizados de manera más "acertada i conveniente" compensarían el pago de nuevos sueldos ${ }^{62}$.

La crítica de los opositores al proyecto se fundaba en tres cuestiones. La primera, la existencia de una idea instalada respecto a que el desarrollo administrativo debe responder al nivel de desarrollo del país. Por ejemplo, una comisión nombrada por el Senado en 1831 para revisar las instituciones levantadas por la Constitución de 1828 señalaba que el principal defecto de una institución era

“...su inadaptabilidad y el no haberse tomado consideración en ellas a las circunstancias de la nación, a la índole y costumbres de sus habitantes, a su educación, al estado de su ilustración, a sus preocupaciones, y aun a sus disposiciones físicas" 63 .

57 Ibid., Sesión 83 a Extraordinaria, 7 de mayo de 1887, 1204.

58 BSS, Sesión $10^{\text {a }}$ Extraordinaria, 17 de diciembre de 1886, 136.

59 Ibid., 135-136.

60 Ibid., Sesión 20a Extraordinaria, 7 de enero de 1887, 268.

$61 B S C D$, Sesión 6 $6^{\text {a }}$ Ordinaria, 16 de junio de $1887,95$.

$62 B S S$, Sesión $10^{\text {a }}$ Extraordinaria, 17 de diciembre de 1886, 138.

63 Citado en Alberto Edwards Vives, La organización política de Chile, Santiago, Editorial del Pacífico, 1943, 117. 
Concepciones en esta línea eran compartidas en la academia. Por ejemplo, Valentín Letelier destacaba las ideas de un pensador italiano llamado Domenico Di Bernardo, cuya obra (Pubblica Amministrazione e la Sociología, editada en dos volúmenes en Italia entre 1888 y 1893) era, según Letelier, la de mayor exactitud en lengua romance en lo que respectaba a la teoría científica de la administración, por lo que, en su opinión, debía ser enseñada en todas las universidades porque explicaba satisfactoriamente la formación, desarrollo y funcionamiento de toda organización administrativa. Di Bernardo planteaba que la administración pública no era una organización independiente de la sociedad, sino que era un órgano de ella, que vivía en y para ella. En esta perspectiva, la administración se desarrolla junto a la sociedad y funciona para satisfacer las necesidades que esta tiene. De esta forma, los países no pueden importar instituciones administrativas superiores a su cultura y que respondan a otro tipo de necesidades sociales $^{64}$. Bajo este esquema interpretativo, los opositores discutían la construcción de un escenario de desarrollo desbordante del país y las tareas del estado, como algo "objetivo".

La segunda cuestión era de carácter valorativo. Existía un sector político que veía la "sobriedad fiscal" como un valor a preservar. Este intento por mantener un Estado pequeño podría estar relacionado con que la oligarquía tuvo temor de quedar a merced de la camarilla que rodeaba al Presidente de la República, una vez que el Estado comenzó a obtener mayores recursos fiscales en la década de $1880^{65}$.

Por último, existía un sector -conservador, principalmente- al que le disgustaba que el gobierno ampliara su ámbito de acción. Por ejemplo, el diputado Balbontín acusaba que el gobierno estaba dando pensiones o becas a personas que caían en gracia de los ministros y se quejaba de que el ministro del Interior creara,

“...por su solo gusto, una clase de telegrafía con su correspondiente sueldo para el profesor, no en la Universidad, sino en la Dirección de Telégrafos, sistema por media del cual podría Su Señoría crear clases en todas las oficinas de su dependencia...Así ¿cómo no se han de aumentar las funciones del Ejecutivo i hacerse necesaria la creación de nuevos Ministerios?"66.

\subsection{Aceptación del nuevo ministerio y reorganización del trabajo en los distintos departamentos}

Si bien existió una oposición, en ciertos sectores del parlamento, a la creación de un nuevo departamento, este rechazo no iba, en específico, contra el de Industria y Obras Públicas. Los opositores al aumento de ministerios no presentaron una solo posición en este punto. Un primer grupo aprobaba su existencia. En él se

64 Valentín Letelier, "La Ciencia del Derecho Administrativo", en Anales de la Universidad de Chile, LXXXV, noviembre-abril 1893-1894, 852-857.

65 Luis Barros y Ximena Vergara, "La Guerra...", 87.

66 BSCD, Sesión 6a Ordinaria, 16 de junio de $1887,99$. 
encontraba el senador Concha y Toro, quien consideraba que los ministerios debían hacerse cargo de servicios de carácter similar, en busca de unidad en la acción. Por ello, convenía la existencia de una cartera que se ocupara de los servicios de “...las obras públicas, caminos, ferrocarriles, correos, telégrafos, i algunos otros servicios, deben formar una seccion..." 67 . En la misma línea, el senador García de la Huerta, planteaba que, hasta ese momento, debido a la falta de un departamento particular,

“... un Ministerio gasta mas que otro, porque el Ministro no se acuerda de sus colegas i decreta la construcción de obras públicas que, a su juicio, son necesarias, sin tomar en cuenta que tambien los otros Ministros tienen necesidad de satisfacer servicios públicos de la misma naturaleza. Es el Ministro de Hacienda quien suele llamar al órden a sus colegas" 68 .

Quienes sí se oponían a la existencia de un departamento particular para la materia, como Eulogio Altamirano, proponían que se organizara la oficina de Obras Públicas y que fuese servida por el ministro del Interior, estando el nuevo servicio a cargo de “...una persona de competencia mui reconocida, que, si es posible, sea una eminencia en el mundo científico"69. Lo planteado por Altamirano daría razones para la creación de la Dirección de Obras Públicas en 1888.

Esta propuesta tuvo respaldo, por ejemplo, en el informe de la minoría de la Comisión de Gobierno de la Cámara de Diputados, presentado el 24 de enero de 1887. Firmado por Jacinto Chacón, el documento señalaba que la nueva Oficina

“...por la especialidad de sus labores no podrá prestar eficazmente sus importantes servicios si se la constituye como un Ministerio de Gobierno... La concentración en una sola oficina de todos los departamentos de obras públicas que se hallan esparcidos en los diferentes ministerios de Gobierno, es una necesidad sentida i debe realizarse con carácter de urgencia; pero la especialidad de las funciones de esta oficina i la tenacidad de los conocimientos de sus jefes, constituye cierta incompatibilidad entre la atmósfera política, en cuyo medio se la obliga a vivir, i las tareas de ingeniería i de obras públicas a que se la destina".

Por ello, proponía que el Jefe de Oficina fuera elegido por sus conocimientos especiales, que ocupara todo el tiempo en esta tarea y que fuera permanente en sus funciones. Señalaba, además, que de ser un funcionario de carácter político, se perjudicaría el funcionamiento de la oficina. La minoría se mostró favorable a que "...se organizase esa gran oficina de fomento como una administración autónoma adherida al Ministerio de lo Interior, quedando el ramo de Colonización siempre anexo al de Relaciones Esteriores i el Departamento del Culto anexo siempre al Ministerio de Justicia..."70. Esta propuesta se basaba en el supuesto de

\footnotetext{
67 BSS, Sesión $10^{\text {a }}$ Extraordinaria, 17 de diciembre de 1886, 135.

68 Ibid., Sesión 20a Extraordinaria, 7 de enero de 1887, 269.

69 Ibid., Sesión 10a Extraordinaria, 17 de diciembre de 1886, 136.

$70 B S C D$, Sesión 32a Extraordinaria, 24 de enero de 1887, 513-514.
} 
que el trabajo administrativo con cierta especialidad era incompatible con el ámbito político.

La Comisión de Gobierno de la Cámara de Diputados planteaba que

“... la aprobación de este proyecto será benéfico para el servicio público, por cuanto es manifiesto que la creación de un Ministerio de Industria i Obras Públicas, como asimismo las innovaciones introducidas en las atribuciones de los Ministerios existentes, responden a satisfacción de necesidades conocidas y lamentadas desde tiempo há en el país"71.

El nombre del nuevo departamento también generó debate. Ello está relacionado con las concepciones sobre la participación del Estado en la economía. En el proyecto se aludía al "Ministerio de Fomento y Obras Públicas". Altamirano -además de la Comisión de Gobierno del Senado- pidió que se borrase del proyecto la palabra "fomento", ya que, en su visión, producía alarmas en los librecambios. Además, planteaba que lo principal del nuevo departamento serían los trabajos públicos y

“... lo accesorio, por ahora i por mucho tiempo mas, estará representado por las medidas que se dicten en protección de la industria, del comercio, de la agricultura o de la minería, en estos ultimos trabajos el Ministerio estará ausiliado por las sociedades que se han establecido con estos fines"72.

La posición del gobierno fue simple. Como el nombre no le gustaba a un grupo de senadores, fue cambiado inmediatamente ${ }^{73}$. No obstante, con posterioridad, en la Cámara Baja, el diputado Enrique Tocornal, pidió que el ministerio fuese de "fomento", pues dicha palabra "...comprende la agricultura, la industria propiamente dicha i el comercio, tres ramos que merecen estar a cargo de un Ministro del despacho"74.

Estas discusiones en torno al nuevo departamento se movieron en dos aspectos: determinar las características de este ministerio u oficina, y el carácter de Fomento o de preocupación por la industria, pero sin el carácter activo del fomento. Dichos puntos se enfocaban en cómo diseñar una institución que, no obstante, no estaba cuestionada en cuanto a la pertinencia de su existencia.

Como algunos parlamentarios contrarios al mayor número de ministerios, no se oponían a la existencia de uno de obras públicas, para no dar paso al aumento de estos, hicieron una serie de propuestas sobre cómo reorganizar el trabajo en solo 5. Para Concha y Toro, con la creación de un ministerio de Obras Públicas, Interior quedaría aliviado de trabajo, por lo que, según él, podría hacerse cargo de las relaciones exteriores, que en "épocas normales" no justificaban la existencia de un

\footnotetext{
71 Ibidem.

72 BSS, Sesión 10 a Extraordinaria, 17 de diciembre de 1886, 137.

73 Ibid. Sesión 20 a Extraordinaria, 7 de enero de 1887, 269.

$74 B S C D$, Sesión 4a Ordinaria, 11 de junio de 1887,65 .
} 
ministerio propio ${ }^{75}$. En la misma línea, argumentó el senador Pereira ${ }^{76}$, y, en la Cámara Baja, el diputado Tocornal ${ }^{77}$. Altamirano, en cambio, se opuso a dicha idea, pues no veía por qué las relaciones exteriores bajarían su volumen de trabajo, como lo insinuaba Concha y Toro, además de plantear que un ministro del Interior podía ser muy mal ministro de Relaciones Exteriores ${ }^{78}$.

Se combatía también, por parte de los conservadores, bajo el supuesto de que la idea de que los ministerios debían tratar ramos análogos, que el Ministerio de Relaciones Exteriores quedara a cargo del Culto, pues los temas que se relacionaban con la materia eran de orden interno. Para el diputado Tocornal, este cambio se había producido por razones nimias y por la voluntad omnipotente que se imponía sobre el decreto-ley vigente de 1837 . Al respecto, decía el diputado Barriga que

"Solo en los últimos años, cuando los Gobiernos invadieron el dominio de las conciencias e impulsaron al país en las vías del liberalismo teolójico i autoritario, solo entonces vimos a la iglesia de Chile tratada como a nación estranjera, casi como a enemiga, digo mal, peor que a enemiga, porque no se guardaron con ella ni las leyes de justicia ni las leyes de la urbanidad"79.

Siguiendo la idea que hacía de la excepción la generalidad, la que parecía justificar el paso de culto a relaciones exteriores, Tocornal decía que, en ese caso,

"La instrucción pública debería estar a cargo del Ministerio de Relaciones Esteriores, porque se mandan traer de Europa los libros... El Ministerio de Hacienda debiera correr a cargo del de Relaciones Esteriores porque en Inglaterra se han levantado los empréstitos... El Ministerio de Guerra i Marina debería correr también a cargo del de Relaciones Esteriores, porque de Estados Unidos i Europa nos vienen las maquinas para la agricultura e industria..." 80 .

Sobre la organización del trabajo, el diputado Tocornal señaló que este proyecto de ley dejaba en pie todos los defectos y vacíos del actual sistema. Incluso planteó que en el país todo había progresado menos la administración pública. Al respecto creía que

"Si se quiere la organización del trabajo, debe este distribuirse diariamente entre las diferentes direcciones de cada Ministerios, direcciones que pueden dividirse según su importancia en uno, dos o mas negociados. Así habría especialidades para cada ramo; i ojalá fuera posible dejar a un lado la política a fin de que atendieran únicamente al buen servicio i no se prestaran a torcidas miras" 81 .

Si ello ocurriera, decía el diputado, la figura del subsecretario sería inútil.

\footnotetext{
BSS Sesión 10ª Extraordinaria, 17 de diciembre de 1886, 135.

Ibid. 139.

BSCD, Sesión $4^{\text {a }}$ Ordinaria, 11 de junio de 1887, 65.

BSS Sesión $10^{\text {a }}$ Extraordinaria, 17 de diciembre de 1886, 136.

$B S C D$, Sesión $6^{\text {a }}$ Ordinaria, 16 de junio de 1887, 94.

Ibid. Sesión 4a Ordinaria, 11 de junio de 1887, 66.

Ibid. Sesión 5a Ordinaria, 14 de junio de 1887, 78.
} 


\subsection{Los empleados ministeriales}

Con respecto a los empleados públicos, la discusión se fijó en tres puntos: cuántos eran; cómo se los nombraba en sus puestos y si trabajaban o no. La cuestión de sus sueldos no provocó mayores resistencias, pues, como dijo el senador Concha y Toro, en esa materia todos estaban de acuerdo que la situación no podía continuar tal como estaba ${ }^{82}$.

El diputado Barriga llamaba la atención a la cámara respecto al número de empleados públicos existentes en Chile en ese momento. Según sus estimaciones, había cerca de 10.000 funcionarios, en circunstancias que los electores alcanzaban las 80.000 personas. Esta cuestión, en su opinión, formaba una importante suma de poder e influencia en manos del Presidente de la República ${ }^{83}$. En tanto, el senador Altamirano, no obstante su creencia de que las administraciones con mayor número de empleados eran más difíciles de organizar, consideraba que el proyecto hacía justicia al mejorar la dotación de empleados ${ }^{84}$.

En la discusión parlamentaria también se hizo referencia al efecto pernicioso que habría tenido en la marcha administrativa la forma de seleccionar el personal público. Según el diputado Barriga, la causa de la deficiencia de la administración no estaba dada por la falta de empleados sino por la existencia del vicio que representaba la intervención política en el orden administrativo, lo que llevaba, en su opinión, a puestos administrativos a intendentes ganadores de elecciones y no a personas con “...conocimientos especiales, larga preparación, acrisolada honradez..."85.

Este llamado por contar con empleados competentes también era compartido por las autoridades del gobierno. Al respecto, el ministro Antúnez destacaba que con los requisitos de estudios establecidos en la nueva ley, se aseguraba la “... manera de que los empleados, por ciertos conocimientos que han de tener para ocupar sus puestos, entiendan los negocios se les encomiendan" $"$.

No obstante, no existía un consenso en los requisitos con los cuales se debía acreditar la competencia. A diferencia del gobierno, el diputado Barriga consideraba inconveniente "poblar de bachilleres" las oficinas públicas en momentos en que la ciencia positiva reclamaba la necesidad de desarrollar estudios de tendencia práctica. Para el diputado, los bachilleres representaban al

“...mismo adolescente de antaño que salia del aula a discutir metafísica con las mozas de la venta, teolojía con el portero del Cabildo i retórica forense con el sastre de la Universidad. Solo que antiguamente los bachilleres solian aprender alguna cosa i ahora se contentan con exhibir una patente del Estado que los habilita para saber de todo, aun cuando no sepan de nada" 87 .

$82 B S S$, Sesión 10 a Extraordinaria, 17 de diciembre de 1886, 134.

83 BSCD, Sesión 6 ${ }^{\text {a }}$ Ordinaria, 16 de junio de 1887, 94.

84 Ibid. 136.

85 Ibid. Sesión $6^{\text {a }}$ Ordinaria, 16 de junio de 1887, 91.

86 Ibid. Sesión 83a Extraordinaria, 7 de mayo de 1887, 1203.

87 Ibid. Sesión 6 $6^{\text {a }}$ Ordinaria, 16 de junio de $1887,92$. 
El diputado Tocornal llamaba la atención respecto a que debía repartirse el trabajo diario de los empleados y dividirse las oficinas en direcciones encargadas de uno o más negociados. Según él, hasta ese momento, los oficiales mayores se dedicaban muchas horas diarias a revisar la correspondencia, antes de repartir el trabajo entre los empleados, que, mientras tanto, esperaban órdenes, sin hacer nada $^{88}$. El ministro Antúnez restaba validez a esa apreciación, destacando que el trabajo era asignado el día anterior ${ }^{89}$.

El diputado Carlos Walker Martínez apuntaba sus dardos contra la falta de laboriosidad de los empleados. Planteaba que, de modo contrario a los actuales empleados, él, durante el tiempo que fue jefe de sección en Interior, puesto que sirvió 10 meses, no recordaba haber dejado trabajo atrasado, aun cuando señalaba no

“...haber llegado a mi oficina ántes de las doce del dia, o nunca me retiré despues de las dos de la tarde. Tenia a mi cargo la primera seccion del Ministerio de lo Interior, que es una de las mas laboriosas; a pesar de esto, jamás dejé una nota sin contestar ni asunto alguno sin que fuera oportunamente despachado" 90 .

Al poner en duda el trabajo realizado por los empleados públicos, los parlamentarios ayudaban a construir una imagen pública difundida en la época, que caricaturizaba a los funcionarios como personas que trabajaban pocas horas al día, cuando iban a hacerlo ${ }^{91}$.

\subsection{Aprensiones hacia las atribuciones del Estado y el Presidente de la República}

En un contexto en el que el que diversos sectores políticos, especialmente el conservador, intentaban disminuir las facultades del Presidente de la República, no es extraño que en la discusión de la reforma ministerial aparecieran algunas aprensiones sobre algunos artículos que, supuestamente, aumentaban el ámbito de facultades presidenciales. Por ejemplo, el proyecto de ley estipulaba que correspondía al Ministerio del Interior preocuparse por la Beneficencia y los cementerios. Para el diputado conservador Manuel Gregorio Balbontín, esas materias estaban constitucionalmente entregadas a las municipalidades, razón por la cual, el ministerio en cuestión no tenía por qué hacerse cargo de dichos ramos.

No obstante, ese no era el único reparo del diputado conservador. Además, Balbontín manifestó que no estaba dispuesto a aceptar que el gobierno, vía decreto,

$88 \quad$ Ibid. Sesión $5^{\text {a }}$ Ordinaria, 14 de junio de $1887,79$.

89 Ibid. Sesión $6^{\text {a }}$ Ordinaria, 16 de junio de 1887, 97.

$90 \quad$ Ibid. Sesión 83 ${ }^{\text {a }}$ Extraordinaria, 7 de mayo de 1887, 1204.

91 Véase, a modo de ejemplo, las siguientes notas donde se construye esta imagen: "La empleomanía a máximo trabalgadas", Padre Padilla, 25 de abril de 1889. "Dirección del Tesoro", El Recluta, 23 de julio de 1891. "Por dentro y por fuera", El Fígaro, 24 de febrero de 1890, "Rodeo de empleados públicos", Poncio Pilatos, 7 de marzo 1895. "De todo un poco", El Fígaro, 16 de septiembre de 1901, "De Actualidad. Un empleado fiscal", El Fígaro, 30 de septiembre de 1901, "De todo un poco", El Fígaro, 20 de julio de 1903. 
tuviera la facultad de vigilar el establecimiento y explotación de los telégrafos particulares, “...pues se puede abusar de ella muy fácilmente" 92 .

El diputado Tocornal, por su parte, llamó la atención respecto a que el Presidente de la República quería organizar el trabajo de los ministerios vía reglamento, como lo establecía uno de los artículos transitorios del proyecto en cuestión. Esta aprensión también se manifestó en la discusión, en el mismo año, sobre la creación del Tribunal de Cuentas y en una polémica sobre la reglamentación del Registro Civil ${ }^{93}$. El tema de fondo radicaba en que a través de los reglamentos las Cámaras no tendrían posibilidades de intervenir en la organización ministerial. Para Tocornal, esa forma de legislar podía ser “...halagadora para los que viven bajo el tutelaje del Gobierno, pero no para los que creemos que debemos llevar nuestra mision en estos bancos por nosotros mismos y no por medio de delegaciones"94.

Otra crítica acusaba que el proyecto entregaba al Presidente la facultad de tener empleados en su despacho y crear oficiales supernumerarios. La resistencia puede entenderse a partir de las concepciones políticas de la época. Para el diputado Tocornal, el Presidente actuaba a través de sus ministros, por lo que no debería tener personal propio. Estos empleados de la "Secretaría del Presidente", al no ser parte de un ministerio, quedaban fuera de la fiscalización parlamentaria, realizada principalmente a través de la existencia de ministros que, con la confianza del Legislativo, estaban a cargo de los distintos ramos administrativos ${ }^{95}$.

Esta aprensión se basa en la desconfianza hacia la relación Jefe de Estadopersonal público, resumida en lo planteado por el diputado conservador Juan Agustín Barriga en la discusión sobre el asunto (ver punto 4.3), cuestión que tenía consecuencias electorales por una serie de acciones que los empleados podían realizar a favor de la intervención electoral, así como por el derecho a voto que estos tenían. Decía Barriga: “¿Quién habla de jenio político en esta pobre tierra i de

$92 B S C D$, Sesión $6^{\text {a }}$ Ordinaria, 16 de junio de $1887,101$.

93 Para seguir la polémica por el reglamento del Registro Civil, véase La Libertad Electoral de los días 14 y 15 de octubre de 1886. En esos días el medio respondía a lo expresado con anterioridad por Los Debates.

94 BSCD, Sesión $5^{\text {a }}$ Ordinaria, 14 de junio de 1887, 79. El diputado Tocornal se mostraba contrario a que se le dieran al Presidente las facultades de tomar ciertas medidas para evitar el cólera, como la expropiación de terrenos o que se tuviesen que informar a las autoridades de los casos de cólera que apareciesen en los hogares. Para Tocornal, "Las facultades que se trata de conceder al Presidente de la República para declarar de utilidad pública lo que se le dé la gana, haciéndolo señor de la vida y las haciendas, es destruir la base misma de la libertad que consiste en la inviolabilidad particular" María Angélica Illanes, op . cit. 69.

95 Ello no implicaba, en todo caso, que el Parlamento ejerciera un control operativo sobre la marcha administrativa. La teoría de la fiscalización parlamentaria decimonónica encargaba al Legislativo realizar un control posterior a las acciones. Cuestión distinta ha ocurrido en el siglo XX, principalmente en Estados Unidos. Al comenzar la administración pública del Estado burocrático a generar normas de carácter general, el legislativo comenzó a realizar un control operativo del funcionamiento administrativo. Sobre estas cuestiones véase Agustín Ferraro, "Control Parlamentario sobre la implementación de políticas públicas. El (escaso) aporte del Congreso a la eficiencia administrativa en América Latina" en Estado, Gobierno, Gestión Pública. Revista Chilena de Administración Pública, Vol. III, N ${ }^{\circ} 8,2006,80-111$. 
qué serviría, cuando las milicias civiles del Gobierno bastan i sobran para ganar la más reñida de las elecciones!"96.

El celo parlamentario por mantener su capacidad fiscalizadora apareció también al discutir lo propuesto por el gobierno respecto al subsecretario. El proyecto dotaba de mayores atribuciones a este empleado en comparación con el anterior oficial mayor. El punto en discusión para los parlamentarios era que el proyecto de ley establecía que los subsecretarios podían asistir a las sesiones del Congreso, cuestión que, en palabras del senador Altamirano, haría ilusorias las capacidades fiscalizadoras del Parlamento, pues al llamar este a un ministro a contestar una interpelación, aquel podría enviar a su subsecretario. Además, destacaba la supuesta inconstitucionalidad de la norma ${ }^{97}$. La Comisión de Gobierno propuso eliminar el artículo en cuestión por la misma razón. Para sus integrantes, aun cuando fuera constitucional y aprobado, en la práctica no debía ser aceptado ${ }^{98}$.

\section{EL BALANCE DE LA PRENSA}

La reorganización de los ministerios fue publicada al mismo tiempo en que se gestaba el tercer Gabinete de la Presidencia Balmaceda. Los medios conservadores, al referirse a la conformación del nuevo Gabinete, no dejaron de lado la aparición de un ministerio más. La Unión de Valparaíso, llegó a sostener que

"No nos sorprenden las dificultades con que... ha tropezado el Presidente de la Republica en la tarea de reorganizar su Gabinete. Ellas tenían que ser el resultado natural de las condiciones impuestas en esa reorganización por los últimos actos políticos del ejecutivo. Para facilitarla se creo un hueco mas en el ministerio. Se pensó... que seria fácil contener a todos los círculos; pero el resultado ha sido, por lo visto, diametralmente opuesto" 99 .

Por su parte, El Independiente criticaba el resultado de la ley, planteando que el gobierno se había apresurado en publicarla, a pesar de las advertencias de los parlamentarios de oposición de retrasar la discusión para que la ley saliera con “... alguna decencia de ropaje que mostrara cierta nobleza i dignidad de orijen". Para el medio, la lógica del proyecto era la siguiente,

"Si hay cinco ministros incapaces, agregue un sexto de la misma calidad. Por lo demás, es indudable que seis comen más que cinco, el país no debe dejar a uno de ellos mirando el festín solo con las del aire" 100 .

\footnotetext{
96 BSCD, Sesión 6 ${ }^{\text {a }}$ Ordinaria, 16 de junio de 1887, 95.

97 BSS Sesión 10a Extraordinaria, 17 de diciembre de 1886, 137.

98 Ibid. Sesión 20ª Extraordinaria, 7 de enero de 1887, 267.

99 La Unión, 23 de junio de 1887.

100 El Independiente, 18 de junio de 1887.
} 
Al margen de cuestiones político coyuntural, asuntos administrativos también fueron tratados. El Ferrocarril vuelve a la discusión sobre las competencias requeridas para ocupar funciones en la Administración. Al respecto, y a propósito del nuevo gabinete, expresó que

\begin{abstract}
"Bajo el punto de vista meramente administrativo, llama desde luego la atención un hecho que no acertamos a esplicarnos por lo que respecta a la distribución de las tareas ministeriales. En la nueva composición del gabinete aparece el señor Cuadra tomando a su cargo el departamento de justicia e instrucción publica y el señor Montt el departamento de industria y obras publicas. Esta distribución no guarda conformidad con las aptitudes especiales, profesión y preferencia de estudios de esos ministros. Hay anomalía al confiar a un injeniero, los ramos de justicia e instrucción publica, y a un abogado, los ramos de industria y obras publicas, sacándolo a ambos del terreno especial de su profesión. No quiere esto decir que estos señores carezcan de una versacion jeneral en ramos que no son de su incumbencia profesional; pero es indudable que su cooperación ofrecería mayores garantía de acierto consagrada a los ramos de su preferencia"101.
\end{abstract}

La Unión también mostró la inquietud sobre el problema de la especialización, no solo de los ministros, sino que también la de los empleados de las oficinas ministeriales. El medio se lamentaba por la forma -a la que no se refiere- en que se estaban nombrando empleados tras la reorganización. Planteaba que el ideal sería seleccionarlos en base al mérito y la competencia. No obstante, ante la imposibilidad de que los ministros se guiaran por estos criterios, apuntaba que

"lo menos que el pais tiene derecho a pedirles y lo menos que ellos tienen el deber de hacer por la buena administracion de los intereses que les están encomendados, es que elijan empleados competentes siquiera para los puestos en que la falta de competencia se traduce por pérdidas pecuniarias, positivas y considerables para el erario nacional.

Que se nombre escribiente de un ministerio a un individuo con caligrafía desgraciada con preferencia a uno que posee la mas hermosa letra; que para una oficina de redaccion se elija a quien tiene su gramática traspapelada, desechando a otro capaz de redactar correctamente; que, en jeneral, para las oficinas de simple tramitacion y de mecanismo manual, se fijen los ministros en sus simpatías políticas o personales, son pecados veniales que el público perdona sin mucho esfuerzo".

Continuaba señalando que la existencia de abogados a cargo de asuntos de marina o médicos a cargo de asuntos de arquitectura, o de ingeniería, generaba errores que debían ser pagados por los contribuyentes. Para el articulista, era poco honrado colocar, en primer lugar, los intereses de favoritos y protegidos de los ministros por sobre el erario nacional.

La crítica de La Unión terminaba con una referencia a la existencia de una fiebre de "extranjerismo". Uno de los casos que mostraba esto habría ocurrido en el Ministerio de Industrias y Obras Pública, donde se contrataron 3 arquitectos

101 El Ferrocarril, 29 de junio de 1887. 
extranjeros, "oficialmente competentes", que no habían sido capaces de entregar planos aceptables técnicamente, cosa que sí pudo hacer un arquitecto chileno, quien no habría cobrado "...ni con mucho, por su trabajo aceptado lo que aquellos cobran por su trabajo inaceptable" 102 .

La Época, en un tono irónico, planteaba que para "La Unión” “...los empleados del Ministerio de Marina deben ser especialistas en la construccion de acorazados, torpederas i máquinas de vapor, en defensa de puertos i en la instalacion de faros, en arquitectura naval i en arte de aparejar, en artillería i táctica de escuadras".

De modo contrario, para el periódico, la tramitación de los asuntos de los ministerios podía ser realizada por personas que contaran con los requisitos educacionales exigidos en la ley de reorganización. Poniendo de ejemplo al Departamento de Marina, decía que los empleados actuaban a partir de informes de oficiales de Marina, lo que salvaría el problema de la competencia en la marcha de ese departamento. La Época combatía la "monomanía del tecnicismo" de La Unión, medio que, en su opinión

“... no se declarará satisfecha mientras no vea entrar i salir en las oficinas de la Moneda graves i doctos hombres de ciencia, sin importarle un ardite que estos especialistas, estos empleados ideales, desconozcan en absoluto las prácticas i procedimientos administrativos que sirven de norma para la solucion de los negocios públicos”.

\section{La parodia finalizaba, apuntando a que}

"El diario porteño tampoco está satisfecho con el nombramiento de los jefes del Ministerio de Industria i Obras Públicas.

La razon es la misma. Los jefes no son especialistas, siendo que, en el sentir de nuestro colega, uno deberia ser un prodijio en la materia de industrias, capaz de abrir un curso de maestros de taller para todo jénero de manufacturas; el otro deberia ser extraordinariamente entendido en arquitectura, en construcciones i en resistencia de materiales, sin que pudiera perdonársele, por ejemplo, la mas insignificante confusion entre un chapitel de órden corintio i uno de órden compuesto..."103.

La discusión en torno a la "monomanía del tecnicismo" va más allá del debate entre gobierno y oposición. Estos artículos ponen en cuestión un problema que alcanza notoriedad en el debate público: ¿qué tipos de empleados públicos se requerían en la administración, generalistas o especialistas?

En todo caso, el debate en torno a los empleados no se agotaba en estas cuestiones, sino que se enfocaba en otros temas, igual de preocupantes para la discusión de la época, como, por ejemplo, las incompatibilidades entre cargos, el nepotismo y la posibilidad de establecer sistemas de carreras en la administra-

102 La Unión, 13 de julio de 1887.

103 "El Ministerio de industria i Obras Públicas", La Época, 17 de julio de 1887. 
ción. La Libertad Electoral pedía que una ley de incompatibilidades por lazos sanguíneos acompañara a la reforma ministerial. Defendiendo su propuesta, afirmaba que

\begin{abstract}
"Es una reforma que constituye prenda de acierto en la elección de funcionarios públicos, de correcto desempeño de sus atribuciones y aun de moralidad administrativa, la que prohíbe que en una misma oficina o servicio puedan existir empleados que entre si estén ligados por vínculos de estrecho parentesco... Esta misma prohibición se declaro comprensiva de los empleados en las oficinas de tesorería i contabilidad por un decreto de 2 de julio de $1883 \ldots$... Por que no se somete a igual condición a todos los empleados públicos?"104.
\end{abstract}

Respeto a lo que debería ser la situación del personal ministerial, señalaba que

"Un ascenso riguroso, fundado en méritos contraídos en el ejercicio de los destinos inferiores, es, por lo jeneral el estimulo más poderoso que puede alentar a los empleados para observar buen comportamiento vinculando su porvenir a la carrera en que por sus aptitudes se hubieren iniciado. Hai así interés en permanecer en el servicio, en que ya se cuenta con algunos antecedentes, aun desechando tentaciones que por el momento se presentan halagüeñas. El favoritismo dispensado por razones de compañerismo político, o de estrechas relaciones de carácter análogo, en beneficio de estraños a la oficina es siempre odioso e irritante para los que, creyéndose con mejores títulos adquiridos en el mismo servicio, tienen que ser victimas de una postergación o desaire que forzosamente lastima la buena reputación de ellos... La estabilidad en los puestos públicos es condición que debe buscarse con ahínco porque ella es siempre base de una competencia adquirida en el trato constante de los negocios sobre que versa el desempeño del empleo..."

Por último, señalaba que los empleados deberían buscar la confianza del subsecretario, mostrándole las capacidades adquiridas, haciendo, de esta forma, “...de la estabilidad de ellos prenda de una buena administración i de propia conveniencia para los ministros" 105 . Con estas ideas, el medio venía a presentar un programa de creación de una carrera que permitiera, a quienes lo quisieran, dedicarse a la administración pública como un campo laboral de largo plazo.

Las bondades de la nueva organización ministerial también fueron destacadas por. La Libertad Electoral. En primer término, apuntaba que "El despacho de los asuntos administrativos no encontrará ya en su ánimo la eterna rémora, siempre alegada de que ocupaciones preferentes del ministro han impedido darle curso...". Señalaba, además, que con la ley concluían las asignaciones por "recargo extraordinario de trabajo", de las que el periódico dudaba su veracidad ${ }^{106}$.

Los Debates destacaba la aparición de un subsecretario con mayores atribuciones que el antiguo oficial mayor, cuestión que los harían “...verdaderos ministros

104 La Libertad Electoral, 17 de junio de 1887.

105 "En los Ministerios", La Libertad Electoral, 2 de julio de 1887.

106 Ibidem. 
administrativos... [y en los] resortes principales de la administración en sus respectivas oficinas". De esta manera, los ministros podrían dedicarse a los asuntos generales del gobierno y a materias de "calificada importancia" y las oficinas se verían aliviadas de "deplorables lentitudes" fruto de la antigua centralización, bajo la cual se necesitaba la firma del ministro para cuestiones "de cajón"107.

La valoración de la aparición de la figura del subsecretario viene a mostrar la existencia en la época de la idea de que lo político y lo administrativo pertenecen a esferas separadas, siendo, por ello, la existencia de responsables políticos y de otros administrativos, beneficiosa tanto para el desempeño del ministro en su relación con el Parlamento como para la marcha del ministerio, a cargo del jefe de servicio, el subsecretario.

\section{CONCLUSIONES}

Las interpretaciones rupturistas en torno a la reforma ministerial de 1887 parecen no tener sustento. Ni la discusión en la prensa ni en el Parlamento dieron muestras de que existiese algún actor político que viese en esta nueva organización atisbos de un intento por darle al Estado un nuevo rol en la economía. Los intentos de Balmaceda por ensanchar la acción estatal y fomentar el progreso, no eran algo nuevo para la época y parecieran ser parte de un pensamiento económico ya instalado. Solamente un parlamentario manifestó que el nuevo Ministerio de Industrias y Obras Públicas podría tener, y en un tiempo futuro, un rol de fomento económico.

Estas cuestiones permiten pensar que la reforma fue un reacomodo, que no alteraba la función de los ministerios, pero que dejaba abierta la posibilidad para una posterior actuación más activa del Estado. En ese sentido, las visiones que afirman la existencia de una continuidad administrativa, y las que plantean un proceso de largo plazo de intervención estatal, parecen interpretar de mejor manera la reforma que se ha estudiado aquí.

Una serie de cuestiones hacen pensar que en materia administrativa existían consensos básicos dentro de la elite. En primer lugar, tras la caída de Balmaceda, los triunfadores no cambiaron las directrices de la intervención pública, salvo en educación y no tocaron la estructura administrativa reformada durante el período Balmaceda ${ }^{108}$, con excepción del establecimiento de una Comisión Parlamentaria en 1892 que buscaba reajustar las plantas de empleados públicos.

A ello se suma la aceptación en todo el espectro político de la necesidad de que existiese una cartera encargada de las Obras Públicas. Esto es importante, pues significa que este nuevo ministerio estaba lejos de ser la institucionalización de un proyecto económico balmacedista divergente del resto del mundo político. Muestra de ello es que, ante la petición hecha por algunos parlamenta-

107 Los Debates, 2 de julio de 1887.

108 John Bowman y Michael Wallerstein, op. cit., passim. 
rios de que no se usara la palabra "fomento" para nombrar a dicha secretaría, el ministro Antúnez no tuvo problema alguno en desistir de nombrar así a la nueva cartera. Incluso, fueron los sectores conservadores los se quejaron por la eliminación de la denominación original.

Las únicas discusiones sobre esta nueva cartera fueron si debía ser servida por un ministro político o si debía ser una dirección y estar a cargo de un empleado técnicamente capacitado. Es decir, se debatía su rango, pero su existencia no estaba en duda. En este sentido, el rechazo al aumento de un "nuevo ministerio" no era un ataque a una nueva organización sino a la creación de un nuevo agente del Presidente de la República, con el rango ministerial.

Los puntos resistidos por los sectores opositores - principalmente conservadores- a algunas cuestiones de la reforma no se sustentaban en visiones antagónicas al gobierno respecto de lo que debía hacer la administración pública. Todos concordaban que las instituciones debían readecuarse a las nuevas situaciones cuando el paso del tiempo las hacía ineficientes. Ahora bien, las causas del desacuerdo se encuentran en que los dos sectores construían distintos diagnósticos sobre el desarrollo del funcionamiento administrativo hacia el momento de la reforma.

Estas distintas visiones no se encuentran solamente en 1887 sino que parecen perdurar por un período más amplio. Por una parte, para quienes contaban con experiencia en el ámbito administrativo, el aumento del trabajo era una "fenómeno real" que superaba a las capacidades de las instituciones ${ }^{109}$. Este diagnóstico planteaba, además, que los empleados eran laboriosos ${ }^{110}$. Ante este escenario, la conveniencia de una reforma resultaba no discutible.

109 Este tipo de explicaciones es recurrente en la autoridad administrativa. Por ejemplo, Carlos Varas, presidente del Tribunal de Cuentas desde 1892, el año en que asume su puesto manifestaba al ministro de Hacienda que los presupuestos más altos provocaban un aumento del trabajo administrativo de su servicio. ANH, AMH, Vol. 2356 "Tribunal de Cuentas 1892-1893", N N4 $^{\circ}$, 5 de noviembre de 1892, foja 44. Recientemente, la Contralora subrogante, Noemí Rojas, señaló que "En 1982, con 1.382 funcionarios, fiscalizábamos gastos del sector público por 14 mil millones de dólares y en 2005 llegamos a casi 48 mil millones de dólares, con un incremento de tan solo 87 personas". Véase $E l$ Mercurio, 30 de julio de 2006, C 10, "Noemí Rojas enfrenta críticas a Contraloría". Tanto en el Tribunal de Cuentas y su sucesor, la Contraloría, la relación con el presupuesto está dada porque estos servicios debían fiscalizar las cuentas fiscales.

El mantenimiento de este tipo de opiniones ayuda a entender la conformación de discursos legitimadores de las autoridades administrativas en momentos en que se cuestiona a las instituciones que van dejando trabajo atrasado.

110 A las Memorias de Hacienda y Guerra de 1886, ya presentadas, se podrían agregar, a modo de ejemplo, la Memoria de Hacienda de 1887, donde el ministro Agustín Edwards planteaba que, a pesar de que los sueldos de la ley de 1853 no permitían exigir contracción y "cooperación inteligente", los empleados de la secretaría habían secundado debidamente sus tareas. Memoria presentada por el Ministro de Hacienda al Congreso Nacional en 1887, Santiago, Imprenta Nacional, 1887, XV. Otro ejemplo en esta línea es la opinión del director de la Contaduría Mayor, José Mateo Fabres, quien decía que sus empleados asistían puntualmente a sus labores. ANH, 1886, AMH Vol. 1601 "Contaduría Mayor 1886-1887", N 2545, 11 de noviembre de 1886. Igual opinión expresaba Alberto Edwards Vives, quien planteaba que en el Departamento de Hacienda se debía trabajar hasta “...altas horas de la noche para no atrasar el despacho...". Alberto Edwards Vives, "Los empleados públicos"; en Pacífico Magazine, volumen 18, abril 1919, 344. 
Por otra parte, se conformó otro discurso, que consideraba los problemas en los servicios como efectos de la existencia de empleados incapaces, incluso fracasa$\operatorname{dos}^{111}$, que llegaban a la administración, gracias al favoritismo político, a hacer nada. De esta forma, en lugar de creer que los progresos del país imponían nuevas cargas a la administración, este grupo pensaba que esta era incapaz de actuar por el tipo de personas que la habitaban.

Además, en la época de Balmaceda, en particular los sectores conservadores y liberales sueltos, creían que el aumento del trabajo administrativo no resultaba de un proceso natural del desarrollo del país sino que derivaba del capricho de un gobierno por actuar en ámbitos que no le correspondían. Ante esta opción del gobierno, los sectores conservadores traían al debate, bajo la categoría de tradición, una serie de valores como la existencia de una administración de tamaño reducido y que era manejada austeramente en sus gastos.

Extrañamente, los sectores de gobierno, por ejemplo Los Debates, a pesar de dar un diagnóstico cercano al colapso administrativo, buscaban, en un inicio, una reforma "sencillísima", que redujera al mínimo las innovaciones, mientras que aquellos que negaban la existencia de un desarrollo administrativo y culpaban a la política como la causante de los males ministeriales, como El Independiente, buscaban reformas más radicales. Esta última actitud puede entenderse pues, al ser la política la razón del mal funcionamiento administrativo, las soluciones debían alterar las relaciones de poder existentes hasta el momento.

Las nociones administrativas de la elite política de la época muestran una sintonía con las principales preocupaciones del desarrollo de la teoría de la administración pública desarrollada durante el siglo XIX y que se constituirán en la base del pensamiento administrativo de la primera mitad del XX. Los principales rasgos fueron la distinción entre política y administración y la preocupación por contar con empleados idóneos.

La distinción política-administración es una de las cuestiones fundamentales de la teoría de la administración pública. En 1812, el francés Charles Jean Bonnin diferenciaba la función del gobierno y la de la administración. La primera significaba dirigir y la segunda, ejecutar. Planteaba que el gobierno no podía actuar sin la administración y que esta no lo podría hacer sin el gobierno ${ }^{112}$. En el mismo sentido, hacia 1900, Frank Goodnow planteaba que la política era la expresión de la voluntad del Estado, mientras que la administración se encargaba de cumplirla ${ }^{113}$.

En el Chile de las décadas de 1880 y 1890 hubo cierto desarrollo académico sobre el tema. Hermógenes Pérez de Arce seguía la línea de pensamiento de Bonnin. Planteaba que la administración pública residía en el Ejecutivo y era el con-

111 Francisco A. Encina, Nuestra Inferioridad Económica. Sus causas, sus consecuencias, Santiago, Editorial Universitaria, 1972, 174.

112 Charles Jean Bonnin, Principios de Administración Pública, México, Fondo de Cultura Económica, 2003 (1812), 319-320.

113 Frank Goodnow, "Política y Administración", en Jay Shafriz, y Albert Hyde (Comp.), Clásicos de la Administración Pública, México, Fondo de Cultura Económica, 1999, 100. 
junto de resortes con los que este movía los servicios que concurrían al bienestar general. Para el autor, el gobierno implicaba desarrollar la acción política del Estado, en tanto administración era la ejecución de “...cada uno de los actos con los que se dan cumplimiento a las leyes de interés general, cuya dirección superior tiene el Gobierno, sin descender este a los detalles que exijen su ejecución, i que corresponden a los funcionarios administrativos"114.

Por su parte, Valentín Letelier criticaba el colocar la administración en un lugar específico del Estado, pues, en su opinión, la teoría de la separación de los poderes se encontraba caduca y los distintos órganos estatales ejercían, a la vez, funciones políticas y administrativas. Para Letelier, la distinción política-administración no era entre órganos sino entre funciones. Las funciones políticas se caracterizaban por ejercer la autoridad para tomar decisiones, cuestión que la distinguía de las funciones administrativas. Letelier compartía la visión de que el gobierno mandaba y la administración ejecutaba ${ }^{115}$.

En el pensamiento norteamericano, hacia 1887 , Woodrow Wilson planteaba que la política era algo distinto de la administración y que esta no debía dejar que manipularan sus funciones. Para Willson, se debía avanzar hacia el establecimiento de la confianza pública hacia los oficiales administrativos, liberando el servicio administrativo del partidismo ${ }^{116}$. En este mismo afán normativo algunos sectores políticos chilenos, críticos a la influencia del gobierno y los Presidentes de la República en la política, utilizaban la distinción. Consideraban que había ciertas funciones, como el manejo de las obras públicas, que eran meramente administrativas. Por ello, no debían colocarse en el ámbito político sino en uno donde la especialización de los empleados representaba una garantía en el trabajo.

Así se entiende, además, la aparición de las propuestas que buscaban instalar un sistema de carrera administrativa para los empleados públicos, además de abordar la cuestión sobre cómo estos debían ser seleccionados. Existía la creencia, no solo de la oposición sino que también de los sectores de gobierno, de que debían mejorarse los sueldos de los empleados. Junto a ello, se planteó la preocupación porque ingresaran a los empleos personas con méritos y preparación para ellos, además de la creación de un sistema de carrera, donde existiese el estímulo del ascenso.

114 Hermógenes Pérez de Arce, El administrador público. O sea estudios sobre principios jenerales, Santiago, Imprenta Victoria, de H. Izquierdo y Co., 1884, 14-15.

115 Valentín Letelier, "Teoría Jeneral de la Administracion Pública", en Anales de la Universidad de Chile, XCIV, julio-diciembre 1896, 561-562.

La diferencia entre las visiones de la administración como parte del Ejecutivo o como una función que ejercen varios poderes se relaciona, según Rutgers, con distintas interpretaciones de la doctrina de la separación de poderes. Según el autor, los europeos continentales adoptaron la noción de la separación total de los poderes, por lo que conceptualizan a la administración como parte del Ejecutivo, algo parecido a lo planteado por Pérez de Arce. De modo contrario, los norteamericanos habrían aceptado la separación de poderes y, además, el balance entre estos. Ello habría provocado que la idea de administración pública norteamericana que surgió en el siglo XX la considere parte del Ejecutivo, del Legislativo y del Judicial. Mark Rutgers, "Public Administration and the Separation of Powers in a Cross-Atlantic Perspective", en Administrative Theory \& Praxis Vol. 22 N $^{\circ} 2$, 2000, 287-308. Esta última idea está explícitamente planteada por Letelier en el artículo arriba mencionado.

116 Woodrow Wilson, “The Study of Administration”, en Political Science Quarterly, Vol. 2. № 2 junio 1887,210 . 
Armando Quezada Acharan, en su memoria para obtener el grado de licenciado en leyes, presentada en 1893 -en medio del funcionamiento de una comisión parlamentaria que estudiaba reorganizar las plantas de empleados de toda la administración-, proponía establecer el empleo público como una carrera definitiva para quienes ocuparan puestos en la administración. En su visión, una larga vida administrativa, basada en tradiciones prácticas que dieran un carácter propio y vigoroso era conveniente para la marcha administrativa. Esto se lograría si la administración contaba con un personal idóneo. Quezada Acharan compartía las propuestas en materia de carrera administrativa presentadas al momento de discutir la ley de $1887^{117}$.

En este sentido, el pensamiento administrativo chileno comenzaba a incorporar características de la burocracia del tipo weberiano. Esto se ve, especialmente, en que la elite creía que la administración era una tarea especializada, que requería una preparación experta y en las propuestas por hacer del empleo público una profesión remunerada con un sistema de carreras con ingreso por capacidades para el puesto y un ascenso en base a la antigüedad ${ }^{118}$.

Existió un sector que, además, se preocupó, por razones políticas, en llevar la separación política-administración al ámbito de los nombramientos de los empleados. Esta cuestión apuntaba a intentar disminuir el poder del Presidente de la República, quien podía contar con sus empleados como electores y agentes electorales, pero, además, se hacía cargo de que esta forma de reclutar funcionarios afectaba la eficiencia de la marcha administrativa.

No resultaría extraño que este grupo político haya mirado la implementación del sistema de servicio civil británico y la dictación de la Pendleton Act en los Estados Unidos. Hacia 1880, en materias de sistemas de personal, el padrinazgo ya era visto en estos países como un mal que afectaba la moralidad y eficiencia de la administración pública. Junto a ello, los exámenes vía concursos abiertos se presentaban como la forma más adecuada y justa para nombrar empleados en sistemas democráticos ${ }^{119}$.

En resumen, en la elite política chilena existían una serie de nociones básicas en torno a la administración. Su rol fundamental dentro de la sociedad no era discutido. Ello no significaba, en todo caso, que no hubiese quejas por el nivel de

117 Armando Quezada Acharan, "La reorganización administrativa en Chile", en Anales de la Universidad de Chile, LXXXIV, 1893, Santiago, 300-301.

118 Vésae, Max Weber, ¿Qué es la burocracia?, sin ciudad, sin fecha, 8, 10, 20, 50, 75 y 115-120. Disponible en http://sociologia.fsoc.uba.ar/documentos/lecturas/Weber_burocracia.pdf [ $1^{\circ}$ de mayo de $2007]$.

119 Los británicos iniciaron la instalación de un servicio civil en 1853. Eliminaron el patronazgo en el reclutamiento de empleados, pasando a ocupar un sistema de exámenes competitivos abiertos, a cargo de una junta central. Además, estableció la promoción interna en los servicios en base a la antigüedad. En Estados Unidos, en tanto, en 1883 se clasificaron una serie de cargos que pasarían a ser llenados vía exámenes de concurso. Se nombraba a los aspirantes con mayores calificaciones en las pruebas, dejándolos a prueba por un tiempo antes del nombramiento definitivo. Edgar Norman Gladden, Una historia de la administración pública II. Desde el siglo XI hasta nuestros días, México, Fondo de Cultura Económica, 1989, 358-372. 
desarrollo y el tamaño que había alcanzado hasta 1880 y que no disgustara, a ciertos grupos, la aparición de algunas funciones no tradicionales.

El pensamiento administrativo del chileno basaba sus planteamientos en elementos propios de una perspectiva liberal, decimonónica y europea, de la administración pública -que la entendía como ejecución de la ley ${ }^{120}$, y vieron aparecer, también, concepciones burocráticas que se hicieron dominantes en el siglo XX. Estas concepciones se mantendrían hasta la década de 1920, en la que la administración comenzó a ser concebida como parte de un proyecto industrializador -siendo su rol planificar y ejecutar en el área económica- ${ }^{121}$. Esta nueva concepción buscaba cambiar el legado burocrático del parlamentarismo por una tecnocracia pública de carácter apolítico ${ }^{122}$.

A pesar que las influencias del pensamiento administrativo decimonónico eran adoptadas por gran parte del mundo político, las interpretaciones políticas de estas ideas podían tener variadas direcciones en el ámbito de la discusión política, principalmente en lo referente al papel del Presidente de la República en el juego político. Otros estudios debieran dar cuenta de esto.

120 Mark Rutgers, "Beyond Woodrow Wilson. The Identity of the Study of Public Administration in Historical Perspective", en Administration \& Society, Vol. 29 N 3 3, 1997, 290-291.

121 Véase Adolfo Ibáñez Santa María, "Los Ingenieros, el Estado y la Política en Chile. Del Ministerio de Fomento a la Corporación de Fomento, 1927-1939”, en Historia, Vol. 18 1983, 48-50

122 Patricio Silva, "State, Public Technocracy and Politics in Chile, 1927-1941", en Bulletin of Latin American Research, Vol. 13 N 3 septiembre 1994, 283. Si bien durante el siglo XIX, como se ha visto, a los empleados públicos se les exigía contar con ciertas credenciales universitarias, estas acreditaban una formación humanista, constituyéndose en una especie de "generalistas". De modo contrario, la tecnocracia a la que alude Silva estaba conformada por ingenieros, quienes, de modo contrario, se asemejan a la figura del "especialista". Sobre las características de los generalistas y especialistas, véase Jean Meynaud, La Tecnocracia, ¿Mito o Realidad?, Madrid, Editorial Tecnos, $1968,37-46$. 